\title{
Ações de internacionalização das atividades das universidades catarinenses: ensaio introdutório
}

\author{
Paola Azevedo* \\ Daniela Lemos ** \\ Dimas Estevam*** \\ Tatiane Viega**** \\ Bruna Furnaletto***** \\ Liana Sonza****** \\ Gustavo Soares $* * * * * * *$ \\ Maria Elizabeth C. Gama******** \\ Jani Floriano $* * * * * * * * *$ \\ Thais C. Rocha**********
}

\section{Resumo}

O objetivo deste artigo é apresentar as ações voltadas a internacionalização das atividades desenvolvidas pelas universidades catarinenses - UFSC, UDESC, FURB, UNIVALI, UDESC, UNIVILLE e UNOCHAPECÓ. As partir de um roteiro estabelecido, os autores buscaram informações nas universidades que estão vinculados. Os resultados apontam que as universidades possuem estrutura organizacional para desenvolvimento de políticas de internacionalização. Formam parcerias e estabelecem convênios com universidades estrangeiras. Em todas universidades, o desenvolvimento dessas atividades mostra-se crescente, sustentado em diferentes ações empreendidas.

Palavras-chave: ações de internacionalização, ensino superior, universidades

\begin{abstract}
The objective of this articles is to presente the actions aimed at the internationalization of the activities developed by the universities of Santa Catarina - UFSC, UDESC, FURB, UNIVALI, UDESC, UNIVILLE and UNOCHAPECÓ. From a established script, the authors sought information from universities thar are linked. The results show thar universities have organizational structure to develop internationalization policies. They form partnerships and establisch agréments with foreign universities. In all universities, the development of these activities is growing, suporte by diferente actioins undertaken.
\end{abstract}

Keywords: internationalization actions, higher education, universities

Classificação JEL: F50; F53; F55

\footnotetext{
* Técnica da Secretaria de Inovação - SINOVA - UFSC. E-mail: p.azevedo4@gmail.com

** Professora do Curso de C. da Administração da UDESC. E-mail: lemosda@ gmail.com

*** Professor do Programa de Pós-Graduação em Desenvolvimento Socioeconômico da UNESC. E-mail: doe@unesc.net

**** Professora do Curso de C. Econômicas da FURB. E-mail: tatianeviega@gmail.com

***** Professora do Curso de C. Econômicas da UNOCHAPEÓ. E-mail: brunaf@unochapeco.edu.br

******Analista de Relações Nacionais e Internacionais da UNOCHAPECÓ. E-mail:

lianasz@unochapecó.edu.br

******* Professor do Curso de C. da Administração da UNIVALI. E-mail: glimasoares@gmail.com

******** Professora e vinculada a Diretoria de Internacionalização da UNIVALI. E-mail: eg@univali.br

$* * * * * * * * *$ Professora do Curso de C. Econômicas da UNIVILLE. E-mail: jani.floriano@gmail.com

$* * * * * * * * * *$ Responsável pela Assessoria Internacional da UNIVILLE. E-mail: thais.rocha@univille.br
} 


\section{Introdução}

A cooperação internacional é um objetivo comum das comunidades científicas mundiais em um mundo cada vez mais globalizado. Tal propósito assegura a qualidade e a eficácia na renovação e na socialização do conhecimento produzido pelas instituições, em diferentes espaços nacionais. Nesse contexto, assume relevância as universidades, cujo papel passa a ser fundamental nestas ações. Torna-se protagonistas da cooperação internacional e promotoras de um processo institucional integrado. Através de ações conjuntas realizadas institucionalmente pode gerar benefícios via processo de internacionalização, destacando: melhor preparação dos alunos na formação de cidadãos globais, diversificação dos estudantes, qualidade do currículo, aumento do perfil internacional da instituição, fortalecimento da produção de conhecimento e pesquisa, cooperação internacional e prestígio dentre vários que surgirão.

A cooperação universitária internacional impacta a formação dos acadêmicos de graduação e de pós-graduação, bem como de professores e pesquisadores universitários. Possibilita agregação de competências internacionais e interculturais. Para os acadêmicos convivência universitária no exterior permite ganhar conhecimento específico da área de formação, bem como o convívio com culturas diversas das suas, com isso obtendo capacidade resolver problemas locais e globais. Da mesma forma, o intercâmbio de professores e pesquisadores através de cursos em nível de pós-graduação - doutorado e pós-doutorado - no exterior, e a realização de pesquisas em conjunto com pares internacionais garantem maior capacidade, para melhor intervenção, por exemplo, na docência e na pesquisa.

Nessa linha, a cooperação acadêmica universitária internacional ganhou destaque nas últimas décadas, em especial em virtude dos desafios correlacionados à atuação da Universidade junto à sociedade. De acordo com Stalivieri (2002), a formação de redes de cooperação pelas universidades e a mobilidade de pesquisadores, professores, estudantes e gestores aproximam as diversas comunidades científicas nacionais e internacionais, as quais possibilitam os avanços científicos e tecnológicos, considerando as particularidades das diferentes nações.

A Internacionalização do ensino superior é um processo em constante evolução. Envolve uma ruptura de paradigmas no ensino vigente até meados do século XX, pois coloca sobre para a universidade a responsabilidade de pensar em novas formas de ensino para atender a um público em ambiente cada vez mais globalizado, que está à procura desta inter-relação. Assim, observa-se que se nos anos 90, o número de acordos de cooperação e de alunos internacionais nos campi das universidades pareciam traduzir o seu grau de internacionalização, nos dias atuais, a relevância da cooperação acadêmica deve se pautar pelo concreto grau de 
cooperação a impactar ambas as partes envolvidas nas dimensões do ensino, pesquisa e extensão.

Nessa perspectiva, o cenário mundial aponta para a expansão da internacionalização do ensino superior, também no Brasil. Cada vez mais, tornou uma necessidade internacionalizar para manter padrões excelência no ensino, pesquisa e extensão. Com a internacionalização se amplia as oportunidades para as universidades, como ferramenta de desenvolvimento e competitividade no cenário nacional e, principalmente, internacional. Os efeitos da internacionalização se manifestam em oportunidades de trabalho e novos aprendizados, num mundo globalizado e intercultural. Além de visibilidade internacional para a universidade e para os acadêmicos, promove espaços para intervenção social da instituição no exterior. Não sem razão, as instituições de ensino superior no Brasil demonstram clareza dos objetivos e das metas que pretendem alcançar. Nessa linha, estão criando, modernizando e desenvolvendo estrutura institucional interna, via constituição de diretoria, secretaria e planos de ação voltados a internacionalização de suas ações.

Em Santa Catarina, algumas universidades já vêm, por décadas, desenvolvendo práticas internacionalizantes em suas atividades, com destaque para a Universidade Federal de Santa Catarina (UFSC), já por sete décadas; outras, já em tempos mais recentes iniciaram suas atividades. A Fundação Universidade da Região de Blumenau (FURB), caminha, nesta rota, por de três décadas. No entanto, outras universidades estão desenvolvendo esforços nesse sentido, sendo referências a Universidade do Estado de Santa Catarina (UDESC), Universidade do Extremo Sul Catarinense (UNDESC), Universidade do Vale do Itajaí (UNIVALI), Universidade da Região de Joinville (UNIVILLE) e a Universidade Comunitária da Região de Chapecó (UNOCHAPECÓ). A suposição é que muitas ações estão ocorrendo nas universidades catarinenses, sem que tenha clareza, de forma agregada, tais ações e seus resultados. Por conseguinte, busca através desse ensaio dar a conhecer, ainda que de forma introdutória, as práticas de internacionalização realizadas por essas instituições de ensino superior.

Para tanto, o artigo encontra-se dividido em três seções, sendo que nessa $1^{\mathrm{a}}$. seção fazse a introdução, contextualizando tema da internacionalização e chamando para uma questão de pesquisa; na $2^{\mathrm{a}}$. seção, descreve-se de forma sucinta as ações que estão sendo desenvolvidas pela UFSC, UDESC, FURB, UNESC, UNIVALI, UNIVILLE, e UNOCHAPECÓ, bem como apresentam-se alguns resultados alcançados; na $3^{\text {a }}$. seção elaboram-se, na forma de síntese, as considerações finais. 


\section{Características da internacionalização das universidades catarinenses: ações e resultados}

\subsection{UFSC}

A cooperação acadêmica universitária internacional ganhou destaque nas últimas décadas, em especial em virtude dos desafios correlacionados à atuação da Universidade junto à sociedade. De acordo com Stalivieri (2002), as redes de cooperação formadas pelas universidades e a mobilidade de pesquisadores, professores, estudantes e gestores aproximam as diversas comunidades científicas nacionais e internacionais, as quais possibilitam os avanços científicos e tecnológicos, considerando as particularidades das diferentes nações.

Em consonância com esta perspectiva, o Plano Institucional de Internacionalização da Universidade Federal de Santa Catarina (UFSC), lançado em 2018, considera a Internacionalização tal qual a definição exposta por Knight (2003), na qual a internacionalização (...) é definida como o processo de integração de uma dimensão internacional, intercultural ou global na finalidade, funções ou entrega de educação pós secundária. O Plano da UFSC ressalta ainda que a internacionalização é reconhecida pelas universidades como um processo essencial para alavancar os índices de excelência em pesquisa e propiciar uma formação que possibilite que a comunidade acadêmica atue e participe de maneira eficaz no mundo globalizado.

O objetivo do Plano Institucional de internacionalização é consolidar o processo de internacionalização da UFSC nos próximos quatro anos, a partir de 2018, a fim de criar e firmar uma trajetória na qual a Universidade possa alcançar o desenvolvimento tal qual uma universidade de classe mundial, ampliando a conscientização internacional e intercultural de discentes, docentes e TAES, bem como propiciando a cooperação internacional e fortalecimento da pesquisa e produção de conhecimento.

Frente a esta conjuntura, as ações de internacionalização da Universidade passam por constante reestruturações. As atuais políticas de internacionalização delineadas no plano da UFSC são a política de linguística institucional, de mobilidade estudantil política, de mobilidade de servidores técnico-administrativos, de mobilidade para servidores docentes e colaboração em pesquisa, política internacional da pesquisa e inovação, de acolhimento, de alianças estratégicas de cooperação, de parcerias cross-border e de apropriação do conhecimento e experiências adquiridas. Cada política é formada por diferentes diretrizes.

O processo de planejamento estratégico institucional de internacionalização acadêmica consta, atualmente, no Plano de Desenvolvimento Institucional da UFSC (2020-2024). As 
principais ações quanto à internacionalização estão subdividas em: ensino, pesquisa, extensão e gestão. A internacionalização aparece como área transversal do PDI em dois objetivos relacionados ao ensino, um objetivo para pesquisa, um para a extensão e outro para gestão. Para cada um destes objetivos são elencados indicadores de desempenho e iniciativas estratégicas. Cabe ressaltar que as iniciativas estratégicas têm como envolvidos e responsáveis a SINTER e demais atores institucionais, tais como PRODEGESP, PROPESQ, PROGRAD, PROPG, SeTIC.

Em relação ao ensino, o primeiro objetivo é de desenvolver competências globais e interculturais e ampliar os programas de intercâmbio e visa à promoção do conhecimento e competências nas diversas culturas através da internacionalização e da intensificação de atividades e dos programas de intercâmbio discente, na graduação e na pós-graduação. Adotouse como indicadores de desempenho para este objetivo a quantidade de turmas de idiomas oferecidas pelo Programa de Educação Tutorial (PET-Letras) e cursos extracurriculares; vagas em cursos de idioma; disciplinas na graduação e pós-graduação ministradas em inglês e outros idiomas; apoio financeiro aos discentes e docentes para apresentação de trabalhos científicos e número de estágios de graduação no exterior.

Dentre as principais inciativas estratégicas, destacam-se o desenvolvimento do programa de internacionalização do ensino; apoio ao processo de mobilidade acadêmica, intercâmbios, dupla diplomação, cotutela e estágios no exterior; estimular a oferta de disciplina em inglês na graduação e pós-graduação e realização de estágio sanduíche de doutorados no exterior; ofertar qualificações para docentes redigirem artigos e projetos internacionais, e para ministrarem disciplinas em inglês; tradução de ementas de disciplinas e sites dos programas de pós-graduação; aumentar os cursos de idioma para a comunidade acadêmica; firmar ações de cooperação com instituições estrangeiras ligadas ao programa PRONT-CAPES/UFSC; estimular a integração acadêmica dos discentes estrangeiros matriculados na UFSC; fomentar a participação de discentes e docentes em eventos científicos internacionais; oferecer curso de português para alunos estrangeiros.

O segundo objetivo relaciona-se ao aumento dos programas de intercâmbio e as ações de mobilidade discente e docente em diferentes modalidades e níveis de ensino com foco na geração de novos conhecimentos, foram definidos os seguintes indicadores: percentual de discentes e docentes que participaram de programas de intercâmbio/mobilidade no exterior apoiados ou não pelos programas de pós-graduação e/ou agências de fomento; número de discentes e docentes internacionais que participaram de mobilidade na UFSC; quantidade de estudantes de graduação que participaram de programas de intercâmbio ou mobilidade no exterior com bolsa; número de acordos de cotutela com instituições estrangeiras; quantidade de eventos internacionais apoiados 
ou promovidos pelos programas de pós-graduação; número de países e instituições com que a UFSC realiza programas de intercâmbio.

Dentre as principais inciativas estratégicas previstas no PDI, destacam-se a criação de programas de intercâmbio de discentes e docentes com universidades estrangeiras; expansão do atendimento aos discentes de convênio; ampliação da contratação de professores visitantes estrangeiros; elaborar e consolidar acordos de cooperação internacional para a pós-graduação; fomentar a vinda de docentes estrangeiro reconhecidos internacionalmente e estimular a participação da comunidade acadêmica em oportunidades de programas de mobilidade internacional.

No tocante a pesquisa, o objetivo vinculado à internacionalização visa fortalecer as relações técnico-científicas com universidades reconhecidas internacionalmente, a fim de aumentar os projetos de pesquisa em colaboração para possibilitar visitas de docentes, TAES e alunos da UFSC a universidades estrangeiras e de pesquisadores e alunos estrangeiros à UFSC. Os indicadores são a quantidade de colaboradores estrangeiros em grupos de pesquisa certificados no $\mathrm{CNPq}$, número de projetos de pesquisa com financiamento internacional e quantidade de acordos de cooperação internacional ativos.

Dentre as principais inciativas estratégicas, aponta-se o estímulo à oferta de cursos de qualificação aos docentes no PROFOR, com foco na redação de artigos científicos bilíngues de alto impacto e a confecção de propostas de projetos internacionais; fomentar as atividades de cooperação com instituições estrangeiras; criar chamadas de propostas para disponibilizar recursos para docentes elaborarem projetos internacionais; produzir um banco de dados da pósgraduação que envolva a pesquisa, intercâmbio de discentes e docentes e outras instituições; fomentar ações com potencial de captação de projetos de pesquisa com parceiros estrangeiras.

E, em relação a extensão, o objetivo planejado é de promoção de práticas extensionistas que visem à internacionalização, com intuito de potencializar experiências em diversos idiomas e culturas. Como indicador de desempenho deste objetivo, destaca-se a quantidade de cursos de extensão ministrado em outro idioma promovido pela Pró-reitoria de Extensão (PROEX). As estratégicas voltadas para a internacionalização no campo da extensão são: criação do núcleo institucional de línguas e tradução para impulsionar a internacionalização; realização de eventos na Universidade a fim de prospectar novos parceiros internacionais; aumento e qualificação dos cursos de idiomas para comunidade universitária; elaboração de materiais das atividades e oportunidades de internacionalização aos discentes e oferta de cursos em língua estrangeira por meio da escola de extensão. 
Ressalta-se que para o currículo e aprendizado algumas ações são a oferta de disciplinas em inglês na graduação e na pós-graduação, tradução dos conteúdos das disciplinas, ampliação dos acordos de cooperação com universidades estrangeiras reconhecidas, definição de critérios para a conversão de notas obtidas em disciplinas cursadas através da mobilidade internacional e emissão de documentos internos da UFSC em língua inglesa. Quanto à estrutura organizacional, a previsão é de alocação de espaço físico adequado para a organização das atividades de internacionalização; expansão dos programas de mobilidade nacional e internacional de TAES; aumento dos cursos de idiomas para a comunidade universitária, aumento de orçamento e de fontes de financiamento para apoio da internacionalização; criar suporte financeiro e operacional para submissão, acompanhamento e prestação de contas para projetos a agências internacionais.

O apoio aos servidores docentes e TAES está centrado na oferta de cursos de qualificação para os servidores ministrarem disciplinas em inglês, redigirem artigos científicos de grande impacto e para criarem propostas de projetos internacionais. Além disso, o apoio está voltado para criação de programas que incentivem docentes a realizar estágio pós-doutoral no exterior; valorização de colaborações internacionais na progressão funcional; valorização da experiência internacional e domínio de línguas estrangeiras como critério para seleção de docentes em concursos públicos; apoio na inclusão dos currículos dos docentes nas plataformas internacionais de pesquisa; aumento na quantidade de projetos de ensino e pesquisa com parceria internacional e ampliação de programas de mobilidade internacional para TAES.

Das ações relacionadas à mobilidade estudantil, a Universidade objetiva estimular a participação de doutorandos em estágios sanduíche; instituir programas de mobilidade para docentes e discentes com universidades estrangeiras e criar dupla diplomação; promover a aplicação de testes de proficiências na UFSC e auxiliar na reformulação dos testes de proficiência aplicados pelo Departamento de Língua e Literatura Estrangeiras; internacionalizar o currículo, por meio da criação e tradução de disciplinas; e recrutar docentes e discentes do exterior.

De acordo com a Sinter (2021), a internacionalização caminha atrelada à história da UFSC. Conforme a linha do tempo histórica apresentada pela Sinter, ainda na década de setenta a UFSC inicia sua participação junto ao Programa de Estudantes-Convênio de Graduação (PEC-G). Em 1972 ocorre a nomeação de Teodoro Vahl como Diretor executivo do Escritório de Assuntos Internacionais (ESAI) e o Reitor João David Ferreira Lima atribui as competências para organizar o Escritório de Assuntos Internacionais (ESAI). Em maio de 2012 ocorre a criação da Secretaria de Relações Internacionais da Universidade Federal de Santa Catarina, a qual permanece na atualidade, sob a gestão do Secretário de Relações Internacionais Lincoln Fernandes. 
Antes da instituição da SINTER, as ações de relações internacionais focavam na recepção de discentes pelo Programa Estudante Convênio de Graduação (PEC-G), o qual compunha a política externa do Brasil, e no intercâmbio com países do Cone Sul. Este cenário era decorrente também da escassez de acesso a recursos externos da época, com exceção dos provenientes dos projetos de cooperação financiados pela CAPES e pelo CNPq e das bolsas do Programa PEC-PG. O aumento das fontes de recursos ocorreu paulatinamente, com o Programa Erasmus Mundus, convênios com bancos e novos convênios e acordos.

A partir da constituição da Secretaria de Relações Internacionais (SINTER), um órgão executivo integrante da administração central da UFSC, diretamente vinculado ao Gabinete da Reitoria (GR), verifica-se a intensificação no processo de internacionalização da UFSC, ampliando a quantidade de convênios internacionais e programas disponibilizados para a comunidade acadêmica e dando origem à Política de Internacionalização da UFSC citada anteriormente. De acordo com o relatório UFSC Números, elaborado pelo Departamento de Gestão da Informação (DPGI/SEPLAN), nos dois anos seguintes à criação da SINTER, o número de acordos internacionais de cooperação assinados pela UFSC passou de 327 para 427. Embora tenha havido uma queda no ano de 2015, houve uma retomada do crescimento dos acordos realizados pela instituição, totalizando 373 acordos em 2019.

Nos três anos anteriores à divulgação do PDI 2020-2024, a internacionalização na Universidade passou a ocorrer por meio de uma visão transversal, partindo do princípio de que o esforço coletivo da comunidade universitária é essencial no alcance da internacionalização. Assim, os objetivos do PDI 2020-2024 vinculados ao ensino, pesquisa, extensão e gestão ligados à internacionalização foram delineados, considerando os diversos atores institucionais. A internacionalização da UFSC é trabalhada atualmente sob a concepção da internacionalização em casa e a internacionalização no exterior.

Conforme o PDI (2020-2024) a primeira envolve atividades que ocorrem em conjunto com outros setores da Universidade, como é o caso dos websites das secretarias e pró-reitorias. A segunda exige mais ações no que diz respeito aos recursos. Mesmo diante desta adversidade, a UFSC tem enviado anualmente 170 alunos para universidades parceiras e 6 servidores TAES por meio da Associação das Universidades do Grupo Montevidéu (AUGM). Além disso, foram celebrados mais de 50 convênios internacionais e aprovados 6 programas Erasmus+ com parceiros estrangeiros.

A SINTER tem como missão "coordenar, desenvolver e expandir o processo de internacionalização da UFSC, com vistas à formação de cidadãos com competências globais capazes de impactar positivamente a sociedade em que vivem, colaborando para a visibilidade e inserção internacional da UFSC em um contexto de inclusão e excelência". Sua visão é ser 
reconhecida pela excelência no processo de internacionalização do ensino superior. Os principais valores desta secretaria são o compromisso ético com a comunidade acadêmica nacional e internacional; a competência e inovação e o respeito pelas diferenças culturais, étnicas e socioeconômicas.

De acordo com o relatório de gestão da Sinter (2020), dentre as atribuições da divisão de gestão da informação, destaca-se a gestão dos dados relacionados à coordenadoria de programas internacionais dos discentes regulares de graduação e pós-graduação e daqueles vinculados ao Incoming e Outgoing, e das coordenadorias de convênios internacionais e apoio administrativo. Esta divisão engloba ainda o tratamento de informações relacionadas aos rankings internacionais, agências regulatórias e elaboração de relatórios, e o apoio na inclusão de Universidades estrangeiras no Programa Print/Capes da UFSC. O setor de tradução atua na tradução de textos institucionais do inglês para o português e da mesma forma converter do português para o inglês, além de interpretar oralmente discursos, debates, e demais demandas do Gabinete da Reitoria e da SINTER.

O Núcleo institucional de línguas e tradução fomenta o alcance das diretrizes da Política Linguística Institucional e apoia a criação de uma base multilíngue sólida, a fim de fomentar a internacionalização nos diferentes dos campi da UFSC. A coordenadoria de apoio administrativo auxilia o planejamento estratégico da Sinter, assessora o diretor e secretário, elabora documentos e materiais oficiais, gerencia material de consumo e patrimônio; planeja e promove eventos e formas de ampliação da visibilidade e presença internacional da Universidade; representa a SINTER na comunidade nacional e internacional. O setor financeiro gerencia orçamento, solicitação de pagamentos, elaboração de relatórios financeiros e prestações de contas da SINTER.

A coordenadoria de convênios internacionais planeja e coordena atividades vinculadas aos convênios, elabora pareceres, instrui processos relativos a convênios, contata instituições internacionais de ensino e pesquisa para o estabelecimento ou renovação de convênios, negociação e elaboração de convênios com instituições de ensino superior (IES) estrangeiras, orienta docentes, discentes e TAES sobre os procedimentos para realização de convênios internacionais.

A coordenadoria de programas internacionais gerencia e operacionaliza os programas que concedem bolsas a discentes regulares e estrangeiros vinculados a programas como: AUGM (Associação de Universidades Grupo Montevideo); BRACOL (Programa de Intercâmbio Brasil x Colômbia); BRAMEX (Programa de Intercâmbio Brasil x México); Universidade de Leiden; Fundación Carolina (Jóvenes Líderes Iberoamericanos); Bolsa Santander Iberoamericana; 
University of Hradec Králove (UHK); ERASMUS + ICM. A coordenadoria de programas internacionais. Existem também atribuições correspondente a movimentação de estudantes no "incoming" e "outgoing", ou seja, relacionadas a atendimento de intercâmbio na UFSC para estudantes ou instituições de ensino internacionais, e orientação de alunos e professores da UFSC e interessados pelo intercâmbio regular, por meio do acordo bilateral.

Dentre os principais objetivos da SINTER, destaca-se a promoção da interação com organismos e instituições internacionais de ensino superior, pesquisa, inovação tecnológica e conservatórios artísticos; fomento do intercâmbio de estudantes, servidores docentes e técnicoadministrativos; apoio e implementação de acordos de cooperação técnica, científica e cultural. Entre os principais Programas Internacionais ativos na SINTER, conforme Silva (2021), destacam-se:

a) Idiomas sem Fronteiras (IsF): objetiva incentivar ações vinculadas à política linguística para a Internacionalização do Ensino Superior Brasileiro;

b) Erasmus: programa de mobilidade de discentes, docentes e TAES, que visa à excelência da educação superior europeia, por meio de parcerias acadêmicas;

c) Programas AUGM: Tem como propósito o aprimoramento contínuo dos discentes da graduação e pós, docentes, gestores e TAES, e da pesquisa científica e tecnológica. A AUGM é formada por universidades da Argentina, Bolívia, Brasil, Chile, Paraguai e Uruguai.

d) Programas GCUB: O Grupo Coimbra de Universidades Brasileiras é dividido em BRACOL e BRAMES e objetivam o fomento de intercâmbio para discentes de nível superior.

e) PEC-G: Oferecido pela UFSC desde 1970, apresenta oportunidades para estudantes provenientes de países em desenvolvimento para realizar a graduação em uma IES brasileira. A UFSC formou mais de 300 alunos e atualmente atende 120 discentes neste programa.

f) USAC: A University Studies Abroad Consortium conveniada com a UFSC desde 2012, oferece bolsas para discente da Universidade cursarem um semestre no exterior, por outro lado, a UFSC recebe estudantes estrangeiros para cursarem disciplinas.

g) Universiteit Leiden: Programa queoferece bolsa para discentes de pós-graduação em Estudos da Tradução, Letras-Inglês, Linguística, Literatura, Filosofia e História, Serviço Social e Relações Internacionais da UFSC.

h) ELAP: O programa Emerging Leaders in the Americas Program viabiliza bolsas para discente de graduação e pós da América Latina e do Caribe para realizarem intercâmbio em universidades do Canadá. 
i) UFSC-UHK: Parceria realizada desde 2015 com a University of Hradec Králove (UHK), da República Checa, objetiva a oferta de bolsa para discentes de graduação e pós e mobilidade de docente de Antropologia, Ciências Sociais, Ciência Política, Arquivologia, Serviço Social, Filosofia ou História.

j) Jóvenes Líderes Iberoamericanos: Seleciona egressos de cursos de graduação da UFSC para realizar intercâmbio em Madrid, Espanha;

k) Santander Iberoamericano: Fomento do intercâmbio de discentes em instituições argentinas, chilenas, colombianas, espanholas, mexicanas, peruanas, portuguesas e uruguaias por meio do financiamento do Banco Santander S.A. do Brasil.

\subsection{UDESC}

A Universidade do Estado de Santa Catarina - UDESC possui uma estrutura multicampi com 12 unidades distribuídas em nove cidades de Santa Catarina, além de 35 polos de apoio presencial para o ensino a distância, em parceria com a Universidade Aberta do Brasil, do Ministério da Educação (UAB/MEC). Em 2020, a UDESC completou 55 anos de sua fundação, registrando mais de 15 mil alunos distribuídos em 60 cursos de graduação e 50 mestrados e doutorados. No que tange à pesquisa, possui 217 grupos credenciados pelo CNPq e no quesito extensão, conta com cerca de 800 ações (UDESC, 2020a).

A UDESC ganhou destaque entre as melhores instituições de ensino superior do mundo em rankings organizados pela Times Higher Education (THE): o World University Ranking, de abrangência global; o Latin American University Ranking, da América Latina; o Golden Age University Ranking, com instituições entre 50 e 75 anos de existência; e o THE Emerging Economies, com universidades de países de economias emergentes (UDESC, 2021c).

A gestão da UDESC no período 2004-2008 “assumiu o compromisso com a abertura das relações de cooperação internacional acadêmica” (UDESC, 2008, p.273). A menção à internacionalização foi realizada no Plano 20 para o período de 2005-2025, em sua Política Institucional de Pesquisa, na diretriz 3: "Desenvolver pesquisas em parcerias com empresas e outras instituições nacionais e internacionais de ensino e de pesquisa, através de projetos compartilhados que objetivem o desenvolvimento regional" (UDESC, 2005, p.115) e na Política Institucional de Pós-Graduação, na diretriz 3: "Para a promoção de cursos de pósgraduação stricto sensu em áreas de menor número de pesquisadores doutores, devem ser oportunizadas parcerias com universidades e instituições de pesquisa nacionais e internacionais, visando à cooperação interinstitucional.” (UDESC, 2005, p. 116). 
Observa-se no atual planejamento estratégico (gestão 2020-2024), nos projetos estratégicos, no que tange à "Excelência em Ensino, Pesquisa e Extensão", os projetos: "Fortalecimento da Graduação e Pós-graduação, mobilidade e Internacionalização" e "Pesquisa em Rede (nacional e internacional)". O primeiro tem como objetivo, "fortalecer o relacionamento da UDESC com instituições nos âmbitos nacional e internacional em prol do ensino, pesquisa, cultura e extensão universitária" (UDESC 2021a, p.13). Dentre as ações estratégicas do referido projeto destacam-se:

\footnotetext{
- Estabelecer convênios com instituições nacionais e internacionais para ampliar a mobilidade de estudantes e professores, para suporte à cooperação acadêmica em matéria de ensino, pesquisa, cultura e extensão universitária, em parceria com agências de fomento;

- Ampliar os programas de capacitação em língua estrangeira, com destaque para o inglês e o português para estrangeiros;

- Ampliar ações para o fortalecimento e internacionalização de cursos de pósgraduação e de graduação (UDESC, 2021a, p.14)
}

Já o segundo projeto possui como objetivo o "estabelecimento de parcerias com entidades nacionais e de outros países para a criação de novos laços de integração e também da manutenção e fortalecimento dos já existentes" (UDESC, 2021a, p.14). Dentre as ações estratégicas relacionadas vale ressaltar: "ampliar as pesquisas em redes no âmbito nacional e internacional e fomentar e desburocratizar o desenvolvimento de pesquisa em parceria com os setores público e privado, nacionais e estrangeiros" (UDESC, 2021a, p.14).

Em adição, o Plano de Desenvolvimento Institucional (PDI) da UDESC (2017-2021), apresenta em seu "eixo 2 - Desenvolvimento Institucional", o objetivo "Promover ações que buscam a internacionalização da universidade". Para o seu alcance são listadas as principais estratégias:

\footnotetext{
- Viabilização de convênios de cooperação com instituições, notadamente latinoamericanas, que guardam excelência em extensão, visando ao aperfeiçoamento teórico-metodológico, bem como a formação de redes extensionistas, com suporte de ferramentas em EAD, além da participação em publicações estrangeiras na área;

- Ampliação da participação de professores em atividades no exterior, por meio do Novo Proeven (Edital Proint);

- Ampliação do número de universidades conveniadas;

- Ofertar disciplinas em inglês;

- Criação e regulamentação da emissão de duplo diploma entre as IES conveniadas internacionalmente nos programas de Pós-Graduação;

- Criação e regulamentação da ação de cotutela entre as IES conveniadas internacionalmente;

- Ampliação de bolsas de mobilidade internacional (Prome), disponibilizando uma vaga anual por curso;

- Participação de técnicos em eventos no exterior (UDESC, 2016, p.166).
} 
Com relação à estrutura institucional voltada à internacionalização, em 2007 foi criada a Secretaria de Cooperação Interinstitucional e Internacional (SCII) como um órgão suplementar superior da Universidade. A SCII tem por objetivo "fomentar as relações entre a UDESC e universidades estrangeiras e brasileiras, visando a gestão e a criação de acordos de cooperação que beneficiem os docentes, discentes e recursos humanos da instituição, além de propiciar um maior destaque da universidade no contexto internacional" (UDESC, 2021b). Dentre as principais linhas de ação da SCII destacam-se a realização de convênios internacionais, os processos de mobilidade acadêmica para estudantes da universidade com ou sem financiamento da UDESC ou por meio de programas específicos e também o auxílio ao aluno estrangeiro.

Segundo o Art.38 do Regimento Geral da Universidade "A Secretaria de Cooperação Interinstitucional e Internacional - SCII é um órgão suplementar vinculado à Reitoria, com um Secretário nomeado pelo Reitor", (UDESC, 2007, p.12) já o Art.39 dispõe sobre as atribuições da SCII:

\footnotetext{
I - estimular a cooperação da UDESC com instituições nacionais e internacionais; II - estabelecer contatos de cooperação e divulgar as atividades da UDESC no país e no exterior;

III - promover e apoiar, em conjunto com os Centros e setores da UDESC, a cooperação com instituições nacionais e estrangeiras, a partir de convênios e acordos; IV - coordenar o intercâmbio de estudantes, professores, pesquisadores e administradores com outras instituições;

V - divulgar informações sobre as oportunidades de intercâmbio e cooperação;

VI - exercer outras atribuições no âmbito de sua competência ou que lhe forem delegadas (UDESC, 2007, p.13).
}

A UDESC possui convênio com universidades dos seguintes países: Alemanha, Austrália, Argentina, Canadá, Chile, Colômbia, Coreia do Sul, Costa Rica, Cuba, Eslovênia, Estados Unidos, Espanha, Finlândia, França, Inglaterra, Itália, México, Moçambique, Noruega, Portugal, Suécia e Uruguai. Dentre os programas de intercâmbio oferecidos pela UDESC, destacam-se o PROME, PIMA e PEC-G.

O Programa de Mobilidade Estudantil da UDESC (PROME), visa ao apoio financeiro dos alunos de graduação da UDESC, para a realização de disciplinas ou outras atividades acadêmicas em Universidades estrangeiras conveniadas, de modo a ampliar seus conhecimentos nas áreas de estudo e possibilitar o aproveitamento das atividades realizadas (UDESC, 2020a). Por meio deste programa, a cada semestre, 12 estudantes da UDESC (um por unidade) recebem auxílio para estudar por um semestre em instituições estrangeiras (UDESC, 2019). 
O Programa de Intercâmbio e Mobilidade Acadêmica (PIMA), do qual a UDESC faz parte, consiste em redes de Universidades Ibero-americanas de intercâmbio de estudantes. Por meio do programa, estudantes estrangeiros são recebidos na UDESC e estudantes da UDESC são selecionados para cursar um semestre, no seu campo de estudos, em uma instituição parceira no exterior. A UDESC faz parte das redes de "Desarrollo Agrario Y Económico: Tendencias Actuales" e “Ciencias Ambientales Y Energías Renovables” (UDESC, 2021b).

O Programa de Estudantes-Convênio de Graduação (PEC-G), criado oficialmente em 1965 pelo Decreto $n^{\circ} 55.613$ e, atualmente regido pelo Decreto ${ }^{\circ} 7.948$, oferece a estudantes de países em desenvolvimento com os quais o Brasil mantém acordo educacional, cultural ou científico-tecnológico a oportunidade de realizar seus estudos de graduação em Instituições de Ensino Superior (IES) brasileiras. O programa é administrado pelo Ministério das Relações Exteriores, pela Divisão de Temas Educacionais, e pelo Ministério da Educação, em parceria com Instituições de Ensino Superior em todo o país (UDESC, 2021b).

No âmbito da pós-graduação, as parcerias internacionais estão previstas e regulamentadas pelo Regimento Geral da Pós-Graduação (Res. 013/2014 - CONSEPE), que dispõe sobre os programas internacionais, conforme menciona o Art. 100 "São objetivos dos Programas de Pós-Graduação Internacionais conjuntos o desenvolvimento de atividades didáticas e de pesquisa em colaboração, com o intuito de reforçar as atividades bilaterais de cooperação internacional". Além disso também são definidas condições para a titulação múltipla entre a UDESC e instituições estrangeiras, bem como as questões envolvendo estudante de instituição estrangeira (UDESC, 2014, p.30).

Os alunos estrangeiros que tiverem interesse em estudar na UDESC contam com um rol de disciplinas oferecidas em inglês, tanto para cursos de graduação como pós-graduação, em várias áreas do conhecimento e centros de ensino. Nos últimos semestres os alunos estrangeiros foram recepcionados em Florianópolis com o Welcome Day, promovido pela SCII (UDESC, 2019). A SCII mantém um programa de "Apadrinhamento/Buddy", com o objetivo de orientar e auxiliar os estudantes internacionais em seus primeiros passos na UDESC. Os alunos da UDESC interessados em fazer o apadrinhamento, podem se inscrever e em contrapartida têm a oportunidade de estar em contato com estudantes de universidades do exterior e de outras culturas, bem como a possibilidade de praticar outros idiomas (UDESC, 2021b).

Em 2019 foi inaugurado o escritório Education USA, o primeiro de Santa Catarina, instalado no Prédio da Reitoria. É um local onde estudantes da UDESC e de outras instituições podem buscar informações para estudar nos Estados Unidos. Vinculado ao Departamento de Estado dos EUA, o Education USA atua com universidades americanas, tendo uma rede de 
mais de 400 escritórios em 175 países, sendo 34 no Brasil. Os escritórios oferecem atividades presenciais e virtuais aos interessados. Os serviços realizados incluem palestras, orientação personalizada e outros procedimentos necessários para efetivação dos pedidos. (UDESC, 2019)

Nas relações de colaboração internacional no campo da pesquisa destacam-se dois programas: o Programa de Auxílio à Participação em Eventos (PROEVEN) e o Programa de Auxílio à Internacionalização da Pós-Graduação (PROINT-PG).

O PROEVEN foi aprovado em 2010 e tem como finalidade "incrementar a visibilidade no exterior da produção intelectual (científica, tecnológica, cultural e artística) da UDESC e propiciar a aquisição de conhecimentos específicos imprescindíveis ao desenvolvimento da pesquisa". Os contemplados pelo programa recebem passagens internacionais de ida e retorno, ajuda de custo e pagamento da inscrição no evento. Desde 2017 a inscrição e seleção passaram a ser realizadas pelas grandes áreas do conhecimento: Grande Área I: Ciências Agrárias, Ciências Biológicas e Ciências da Saúde; a Grande área II: Ciências Exatas e da Terra, Engenharia, Multidisciplinar; Grande Área III: Ciências Humanas, Ciências Sociais Aplicadas, Linguística, Letras e Artes (UDESC, 2017). No período de 2014 a 2020, 111 professores foram contemplados pelo programa (UDESC, 2020b).

O PROINT-PG foi aprovado em 2017 e teve seu primeiro edital lançado em março de 2018. O programa oferece apoio (passagens e diárias internacionais) para professores, integrantes de cursos de doutorado, participarem de atividades de pesquisa ou pós-graduação no exterior (UDESC, 2018). Em 2018, o PROINT-PG contemplou 5 projetos; no ano de 2019 contemplou 8 projetos; já no ano de 2020 não pôde contemplar nenhum projeto devido à pandemia do coronavírus (COVID-19) (UDESC, 2020b).

\begin{abstract}
O PROINT-PG tem por finalidade apoiar a realização de estágio de curta duração por docentes pesquisadores de programas de pós-graduação da UDESC, integrantes de cursos de doutorado com conceito CAPES 4, 5 e 6, para realização, no exterior, de atividades de pesquisa conjunta com pesquisadores estrangeiros vinculados a projeto em andamento no Brasil ou no exterior; ou atuação em programas de pós-graduação estrangeiros que contribuam para a ampliação das possibilidades de colaboração com pesquisadores estrangeiros, incentivem a incorporação à redes internacionais, possibilitem a produção acadêmica conjunta e consolidem colaborações futuras que revertam em prol da internacionalização dos programas de pós-graduação da UDESC (UDESC, 2017, p.115).
\end{abstract}

No que diz respeito à internacionalização das ações de extensão, pode-se destacar a atuação do Grupo Coordenado em Gestão de Riscos e Desastres (CEPED), no plano de cooperação humanitária internacional, por meio do convênio com o Programa das Nações Unidas para o Desenvolvimento (PNUD) para a elaboração de um plano de cooperação 
humanitária internacional no Brasil, no âmbito do projeto de fortalecimento da cultura de gestão de riscos de desastres no país, através do Ministério da Integração Nacional. Destacam-se ainda, no âmbito do CEPED as ações de capacitação de pessoal na gestão de riscos e redução de desastres em Santa Catarina, por meio do convênio técnico-científico com a USAID/PFDA (UDESC, 2020c).

Em 2017 a UDESC sediou o $42^{\circ}$ Encontro Nacional do Fórum de Pró-reitores de Extensão das Instituições Públicas de Educação Superior Brasileiras (Forproex), com a participação de representantes de 70 instituições de ensino superior. Na oportunidade foi assinada a Carta de Florianópolis, documento que faz menção à ampliação e ao fortalecimento da política de internacionalização da extensão (UDESC, 2018). Em 2019 foi aprovada a nova Política de Extensão Universitária da UDESC, que prevê em sua agenda estratégica a internacionalização das ações de extensão (UDESC, 2020c).

No que diz respeito ao estímulo a criação de vínculos com centros universitários e institutos de pesquisa no exterior, os professores fazem contato diretamente com as universidades internacionais em projetos de pesquisas conjuntos. A partir desses contatos, podem ser firmadas parcerias, estendendo-se a mobilidade para alunos, professores e técnicos. A SCII mantém contato permanente com universidades internacionais, auxiliando na formulação de parcerias quando há interesse institucional. Além disso, as agências de fomento informam sobre oportunidades internacionais para alunos e professores que são divulgadas internamente pela SCII.

A UDESC faz parte da Associação Brasileira de Educação Internacional (FAUBAI), Grupo Coimbra de Universidades Brasileiras, além da representação do Education USA. Estas associações permitem o acesso a oportunidades de bolsas para graduação e pós-graduação no exterior de países diversos. As informações relacionadas são divulgadas pela SCII via e-mail e nos canais de divulgação da UDESC. Da mesma forma é feita a divulgação referente às oportunidades oferecidas por órgãos governamentais e agências de fomento. Embora estes últimos não tenham uma ligação direta com a UDESC, todo o suporte institucional necessário é dado à comunidade acadêmica para viabilizar os acessos as bolsas e as parcerias para que mais grupos sejam beneficiados. Por fim, cabe registrar que a UDESC conta com o canal "Podcast Intercâmbio", disponível nas principais plataformas de áudio, para divulgar informações relacionadas à intercâmbio, incluindo entrevistas com alunos, dentre outros (UDESC, 2021b). 


\title{
2.3 FURB
}

A preocupação com a internacionalização da FURB pôde ser observada com a criação da Coordenadoria de Relações Internacionais (CRI), mais precisamente em 11 de maio de 1988. Já a partir desse ano a CRI promoveu a internacionalização a partir de dois programas, o Programam de Cooperação Cultural e Educacional entre Brasil e Itália, o Programa de Cooperação Interuniversitária (Espanhol). No mesmo ano recebeu a visita da Comitiva da Califórnia State University, assim, recebeu aprovação para iniciar o programa de intercâmbio através da Internetional Association for the Exchange of Students for Technical Experience IAESTE (FURB, 1998).

Nos anos seguintes a FURB estabeleceria convênios de forma efetiva e contínua com Instituições de Ensino Superior da Europa, América do Norte, América Latina, Ásia e África. O objetivo traçado pela Universidade de Blumenau, já buscava promover a qualificação e atualização do conhecimento, compreendendo-se que a internacionalização seria parte fundamental das relações universitárias em todos os níveis de ensino.

A importância dispensada ao processo de internacionalização fica evidenciado através do Plano de Desenvolvimento Institucional do ano de 2010, revisado nos anos de 2013/2014 quando se lê,

\begin{abstract}
A FURB, em sua Visão, firma um compromisso de "ser uma Universidade pública, reconhecida pela qualidade da sua contribuição na vida regional, nacional e global". Em seus Valores, a Universidade se compromete em "[...] inovar nos processos de Internacionalização". Fica evidenciado que a internacionalização é um objetivo da FURB e que há intenção de ampliação de seus acordos de cooperação internacional nas mais diversas áreas do conhecimento. Convém destacar a preocupação institucional em manter a excelência no ensino, na pesquisa e na extensão (PDI, 2014, p.112).
\end{abstract}

Em 2011 a FURB aderiu ao Programa Ciência sem Fronteiras do Governo Federal que tinha como objetivo "promover a consolidação, expansão e internacionalização da ciência e tecnologia, da inovação e da competitividade brasileira por meio do intercâmbio e da mobilidade internacional" (FURB, 2012, p.203). O programa oferecia bolsas de estudo, podendo o estudante fazer intercâmbio em instituições internacionais pelo período de um ano. "Em 2013, a FURB consolidou a parceria, enviando 15 (quinze) discentes para diversos países da Europa, Oceania e América do Norte" (PDI, 2014).

A FURB considera a importância de estimular as práticas de internacionalização haja vista que, 
a) O estudo em outros países contribui para a formação de um profissional autônomo e globalizado, capaz de atuar e resolver problemas em qualquer lugar do mundo;

b) Permite a convivência com pessoas de outros países estimulando a empatia, a tolerância, a solidariedade, o respeito pelo outro e a diversidade cultural, características necessárias ao trabalho de equipe;

c) Os estudantes e professores estrangeiros trazem elementos culturais, econômicos, linguísticos, comportamentais e geográficos que enriquecem a sala de aula;

d) Proporciona ao egresso o aumento de empregabilidade em todo o mundo e amplia o networking em escala global;

e) Pode proporcionar ao estudante receber o diploma assinado por sua universidade de origem e pela instituição na qual estudou no Exterior, quando previsto em convênio específico. (PDI, 2017).

\section{Em 2018 a FURB atualizou os objetivos no que tange a Política de Internacionalização e assim ficaram definidos,}

I. Produzir novos conhecimentos nas diversas áreas do saber;

II. Contribuir para o desenvolvimento, sustentabilidade e visibilidade da Instituição.

III. Contribuir para o desenvolvimento acadêmico, cientifico, tecnológico, artístico, cultural e pessoal dos estudantes em todos os níveis de ensino;

IV. Contribuir para a complementação da formação de docentes, discentes e demais servidores proporcionando-lhes novas vivências e oportunidades;

V. Estabelecer cooperação cientifica efetiva com universidades e/ou entidades de pesquisa no mundo;

VI. Proporcionar o aumento do número de pesquisadores estrangeiros na Instituição; VII. Estimular o desenvolvimento de programas internacionais conjuntos de pósgraduação;

VIII. Constituir-se num diferencial competitivo da Universidade, auxiliando no fortalecimento da marca FURB;

IX. Ser agente motivador da transformação da realidade dos cursos e da consolidação da pesquisa;

$\mathrm{X}$. Estimular a multi, a inter e a transdisciplinaridade;

XI. Interagir com o público estrangeiro (stakeholders) da FURB e construir relações sólidas que contribuam para o desenvolvimento regional, social, cultura, econômico e educacional;

XII. Contribuir para a adoção de uma concepção de ensino que instigue a geração do conhecimento entre docentes, discentes e demais servidores a partir da exploração de processos cognitivos inovadores e criativos;

XIII. Contribuir na promoção da difusão do conhecimento cientifico gerado na pesquisa por meio de ensino e extensão, publicações cientificas qualificadas em periódicos, livros com conselho editorial, eventos, mídias e hipermídias diversas, e XIV. Fomentar a internacionalização dos campi, das disciplinas e dos currículos dos cursos, por meio do uso de línguas estrangeiras, da cooperação em rede, do desenvolvimento de competências comunicativas interculturais dos docentes, discentes e servidores, da mobilidade e do intercambio docente e discente, publicações cientificas em periódicos internacionais, entre outras atividades. (PDI, 2018, p.145146).

Entre os anos de 2010 até 2015 a Coordenadoria de Relações Internacionais acolheu 253 estudantes e 37 professores estrangeiros. Encaminhou ao exterior 402 estudantes e 33 professores, assinou 42 novos convênios e promoveu diversos eventos e atividades que visaram a cooperação internacional conforme dados demonstrados no Tabela 1 do Relatório de Atividades (FURB, 2015, p.113). 
Tabela 1 Atividades desenvolvidas pela FURB no âmbito de relações internacionais, 2011 2015.

\begin{tabular}{l|c|c|c|c|c|c}
\multicolumn{1}{c|}{ Atividades } & $\mathbf{2 0 1 0}$ & $\mathbf{2 0 1 1}$ & $\mathbf{2 0 1 2}$ & $\mathbf{2 0 1 3}$ & $\mathbf{2 0 1 4}$ & $\mathbf{2 0 1 5}$ \\
\hline Convênios assinados & 13 & 8 & 5 & 8 & 1 & 7 \\
\hline Estudantes estrangeiros acolhidos & 32 & 55 & 31 & 56 & 28 & 51 \\
\hline Professores estrangeiros acolhidos & 3 & 7 & 11 & 5 & 3 & 8 \\
\hline Estudantes encaminhados ao exterior & 63 & 65 & 58 & 74 & 90 & 52 \\
\hline Professores encaminhados ao exterior & 4 & 5 & 12 & 5 & 3 & 4 \\
\hline Projetos realizados & - & 2 & 3 & 3 & - & - \\
\hline Eventos organizados & 5 & 8 & 4 & 4 & 6 & 13 \\
\hline Participação em eventos & 3 & 3 & 3 & 3 & 6 & 5 \\
\hline Visitas recebidas & 15 & 22 & 24 & 30 & 19 & 21 \\
\hline Assessoria a viagens & - & 1 & 2 & 4 & - & - \\
\hline Disciplinas ofertadas em inglês & - & - & - & 3 & 7 & 8 \\
\hline Fonte: Coordenadoria de Relações Internacionais - CRI
\end{tabular}

A Coordenadoria de Relações Internacionais - CRI é o órgão que promove a internacionalização na Instituição, atualmente conta com um coordenador e técnicosadministrativos que auxiliam estudantes e professores da FURB de todos os níveis, desde ensino médio até o stricto sensu que queiram realizar intercâmbio nas instituições conveniadas. "Compete à CRI orientar, acolher e acompanhar docentes, pesquisadores e discentes estrangeiros (incoming), assim como a orientação aos docentes pesquisadores e discentes da FURB que estejam saindo (outgoing) para intercâmbio, além de suporte a projetos no âmbito da internacionalização" (PDI, 2018). As ações são as mais variadas, indo desde o intercâmbio acadêmico até a capacitação do quadro de servidores da Universidade. Atualmente, a Universidade mantém diversos convênios com instituições de ensino superior no exterior, sendo, 10 países na América, 9 países na Europa, 3 na África e 2 na Ásia.

Além do intercâmbio, existem outras ações que buscam fomentar a internacionalização como a possibilidade de cursar disciplinas lecionadas completamente em inglês, alemão e espanhol. Ainda é importante ressaltar que o curso de Tecnologia em Marketing da FURB é um exemplo de tecnólogo elaborado conjuntamente com a experiência da internacionalização, teve sua base no curso de Ciências da Administração e Economia de Halmstad, o que permite a dupla diplomação, uma qualificação a mais no currículo dos formados. Atualmente este convênio está suspenso.

Outra ação direta é o programa “Amigos do Mundo" que incentiva o maior contato entre comunidade acadêmica e alunos estrangeiros, possibilitando que alunos da FURB recebem em suas casas estrangeiros das demais instituições conveniadas. Para além do idioma, esse programa tem o objetivo promover a troca de experiências culturais, hábitos, estilos de vida entre aqueles que acolhem e os que são acolhidos. 
De acordo com dados constados nos PDIs da FURB, pode se observar a mobilidade acadêmica através do envio e recebimento de estudantes e professores junto as universidades parceiras. Em 2013 foram enviados 58 estudantes, 5 professores e recebidos 41 estudantes e 5 professores. Em 2015 foram enviados 41 estudantes e recebidos 51. Em 2017 foram enviados 71 estudantes, acolhidos 27 e 3 docentes. Vale ressaltar que o intercâmbio docente "tem por finalidade o desenvolvimento de atividades correlatas a docência, pesquisa e extensão na instituição de destino" (PDI, 2017, p.127).

Ainda conforme os PDIs revisados em 2014, 2017 e 2018, em relação aos acordos e convênios firmados com instituições estrangeiras, em 2014 haviam 58 acordos e convênios com universidades estrangeiras em 21 países diferentes. Em 2016 eram 62 acordos e convênios mantendo os mesmos países, já em 2017 eram 72 parcerias com 22 países, entre eles Alemanha, China, Argentina e Canadá. Esses acordos e convênios possibilitaram a mobilidade de estudantes de graduação e pós-graduação stricto sensu assim como de docentes.

Em 2018, a Universidade aprovou o Programa Idiomas sem Fronteiras (ISF), estando subordinado ao Programa ISF da Secretaria de Educação Superior (SESu) do MEC, tendo como objetivo geral contribuir para a política de internacionalização, com ações direcionadas para o ensino, pesquisa, extensão e cultura, por meio da ampliação de oferta de cursos em outros idiomas. Ainda em 2018 foi instituída a Política Linguística da FURB, com o objetivo de:

Definir estratégias institucionais que atendam aos pressupostos da formação linguística, da internacionalização do ensino, da pesquisa, da extensão e da cultura, valorizando as relações interculturais, a inclusão social e a diversidade cultural, tomando por referência a formação integral, o respeito à diversidade e à solidariedade. (PDI, 2018, p.155).

Conforme exposto através dos vários relatórios institucionais, a FURB, consolidou-se ao longo de 23 anos no que tange as ações em busca da inserção da Universidade no processo de internacionalização. Desde a criação da Coordenadoria de Relações Internacionais até o presente momento, foram diversos estudantes e professores acolhidos e enviados ao exterior com os mais variados objetivos, desde visitas técnicas, de reconhecimento até o intercâmbio acadêmico. A parceria permanece com mais de 70 universidades em mais de 20 países. Ainda é importante ressaltar que toda a mobilidade se dá desde o ensino médio até os programas de pós-graduação, ou seja, engloba ensino, pesquisa e extensão. 


\subsection{UNESC}

As políticas de internacionalização da UNESC baseiam-se em fundamentos de transversalidade, interdisciplinaridade, inovação e internacionalização na articulação das áreas do conhecimento. Compreender que a internacionalização constitui uma parte importante da experiência formativa dos alunos, de todos os níveis e modalidades, significa reiterar que o processo de internacionalização possibilita a troca de experiências, desenvolve o espírito colaborativo, o trabalho em conjunto e, principalmente, no convívio com a diferença e com o desconhecido (PDI 2018-2022).

Instituída em 2018, a Política de Internacionalização da UNESC foi aprovada oficialmente, pela Resolução $\mathrm{n}^{\underline{0}}$ 03/2018/CONSU (Conselho Universitário), embora, a atividade tenha sido iniciada muito antes da aprovação desta Resolução. O conceito de internacionalização adotado pela Universidade se constitui como um princípio educacional que tem por intuito vincular o ensino superior ao contexto de trânsitos transnacionais e interculturais característicos do mundo globalizado (RESOLUÇÃO 03/2018). O objetivo da política de internacionalização da UNESC é desenvolver ações estratégicas visando o fortalecimento das relações com instituições internacionais, inserindo a instituição no cenário internacional do ensino, da pesquisa e da extensão, objetivando promover o bem-estar da sociedade. Estas ações estão divididas em quatro eixos norteadores: ampliação da estrutura de internacionalização; qualificação do corpo docente e discente em língua estrangeira; potencialização de parcerias e acordos de cooperação com instituições estrangeiras e; fortalecimento dos Programas de Pósgraduação stricto sensu (RESOLUÇÃO 03/2018).

A prática de internacionalização das atividades da Unesc, foram iniciadas em 1996, com criação da Coordenadoria de Relações Internacionais, posteriormente transformada em Escritório de Relações Internacionais (International Relations Office). O Escritório tem por objetivo fomentar, apoiar e promover as relações internacionais da Unesc com universidades estrangeiras com mútuo interesse em desenvolver mobilidade acadêmica, pesquisas, intercâmbio discente/docente, palestras, por meio de contato do próprio setor bem como de outros agentes envolvidos no processo. Como prioridade busca orientar e acompanhar as ações de parceria, os convênios com instituições de ensino e organizações estrangeiras, bem como nacionais de fomento à cooperação internacional. (PDI 2018-2022).

A estrutura organizacional da Política de Internacionalização da UNESC é executada pelo Escritório de Relações Internacionais, vinculado diretamente à Reitoria, constituída por um Comitê Gestor, formado: pela Pró-Reitora Acadêmica, como presidente; Pró-Reitor de 
Planejamento e Desenvolvimento Institucional; pelos Diretores de Ensino de Graduação, de Pesquisa e Pós-Graduação e de Extensão, Cultura e Ações Comunitárias; um pesquisador de Programa de Pós-Graduação; um coordenador de curso de graduação; um representante do corpo discente dos cursos de pós-graduação; um representante do corpo discente dos cursos de graduação (RESOLUÇÃO 03/2018).

O Escritório de Relações Internacionais é a unidade administrativa cuja missão é promover e apoiar a internacionalização da Universidade, como meio para atingir a excelência na atividade acadêmica. Visa formar cidadãos e profissionais inseridos da comunidade global. Entre os valores que dirigem as ações do Escritório de Relações Internacionais estão a interculturalidade, a inclusão, a equidade, a inovação, a presença e a solidariedade em nível global (RESOLUÇÃO 03/2018).

O Escritório de Relações Internacionais, tem como principais atribuições: desenvolver a política de cooperação internacional da Instituição; assessorar a reitoria no desenvolvimento da política de cooperação internacional em todos os níveis e modalidades; constituir-se em um foro central de todos os assuntos internacionais referentes à Instituição e aos polos de apoio presencial; promover, em conjunto com os diversos setores da Universidade, ações de parceria, convênios e intercâmbios com instituições de ensino, governos e órgãos não governamentais internacionais; divulgar informações sobre convênios, intercâmbios, cursos, estágios, bolsas de estudos e programas de instituições governamentais e não governamentais para toda a comunidade acadêmica em todos os níveis e modalidades.

Entre as principais atividades do Escritório de Relações Internacionais estão: a recepção de visitantes e delegações internacionais; a negociação e condução interna de acordos de cooperação com universidades estrangeiras; diversas atividades de recepção e acolhida de estudantes e professores estrangeiros; o apoio na alocação de residências e o suporte em processos administrativos internos e externos, tais como a obtenção de documentos brasileiros, relacionamento com a Polícia Federal e a obtenção de visto para professores estrangeiros, entre outros.

O processo de internacionalização acadêmica da UNESC consta do Plano Desenvolvimento Institucional (PDI 2018-2022). A internacionalização se configura como um processo pedagógico e formativo, que ocorre por meio de acordos de cooperação técnica, científica e cultural, firmados com instituições de ensino superior, de pesquisa e outras instituições relacionadas à área de interesse. Esses processos envolvem atividades de intercâmbio de professores, estudantes, pesquisas, publicações, internacionalização de matrizes curriculares, dupla certificação e formação em línguas estrangeiras. (PDI 2018-2022). 
A construção e a manutenção de programas de intercâmbio com universidades estrangeiras são vistas como um importante componente formativo do acadêmico. Segundo as informações obtidas juntos ao Escritório de Relações Internacionais foram realizados 202 minicursos e complementações cursadas no exterior, em diversos tipos de convênios. Estas atividades fizeram com que os estudantes tenham um diferencial na sua formação e no seu currículo. Como instrumento de apoio a internacionalização, a Unesc conta com o Instituto de Idiomas que oferece aulas de alemão, espanhol, inglês, italiano, francês e português para estrangeiros. Além disso, o Instituto de Idiomas presta serviços como traduções, elaboração de provas de proficiência e está credenciado para aplicação do Toefl. O diálogo e o relacionamento com outras culturas, países e nacionalidades, bem como, o intercâmbio científico-acadêmico e a mobilidade acadêmica fazem parte dos pilares do desenvolvimento institucional da UNESC.

Atualmente, a UNESC mantém 47 acordos e/ou convênios internacionais com diferentes universidades e países e, em especial, por meio de seus programas de pós-graduação stricto sensu. Dentre os países cita-se os seguintes: Alemanha, Angola, Argentina, Canadá, Chile, Colômbia, Espanha, EUA, França, Inglaterra, Irlanda, Itália, México, Paraguai, Portugal, República da Macedônia, Rússia, Suíça, Uruguai, entre outros.

Conforme informações obtidas junto ao Escritório de Relações Internacionais, desde 2008, a UNESC enviou 109 alunos de graduação e 2 de pós-graduação (Mestrado) para intercâmbio no exterior, através do Programa de Mobilidade Acadêmica da Unesc, Programa Santander Universidade, ELAP e Ciência sem Fronteiras. Além disso, a Unesc recebeu 29 alunos estrangeiros de graduação, 1 de pós-graduação (Mestrado) e 12 alunos para a Residência Multiprofissional. Também, possui 68 alunos estrangeiros matriculados em cursos de graduação e pós-graduação.

\subsection{UNIVALI}

A UNIVALI iniciou a prática de internacionalização de atividades em 1992, com a criação da Assessoria de Assuntos Internacionais (AAI). Essa gênese pode ser associada ao interesse e disposição da reitoria em reconhecer a importância e a necessidade de se expor a comunidade acadêmica a uma formação mais identificada com os paradigmas da globalização. Com a criação da Pró-Reitoria de Pesquisa, Pós-graduação e Extensão, em 1994, o campo de ação da a AAI (então renomeada Coordenadoria de Assuntos internacionais- CoAI) começou a ser melhor identificada, pois o processo de institucionalização da pesquisa e da pós-graduação 
fez-se acompanhar por um maior entendimento acerca do real lugar da cooperação internacional na universidade na formação de pesquisadores e docentes.

Os primeiros objetivos foram traçados, de forma assistemática, pelo então assessor para assuntos internacionais e pelo reitor. Esses objetivos eram limitados à assinatura de acordos marco e de mobilidade acadêmica com universidades portuguesas, espanholas e italianas, para permitir o intercâmbio de alunos e professores e, eventualmente, uma possível coautoria em artigos científicos e a realização de eventos conjuntos.

O processo de internacionalização da UNIVALI é parte do Planejamento Estratégico Institucional, que se norteia pela Política de Internacionalização, aprovada em 2016 e com objetivos e metas a serem cumpridas até 2021. As principais linhas de ação são:

- Intensificação da rede internacional de pesquisa dos programas de pós-graduação;

- Equilíbrio dos indicadores de mobilidade In e Out;

- Ampliação da diversidade linguística, cultural e geopolítica dos acordos de cooperação internacional;

- Fomento para criação de programas voltados à formação de uma mentalidade global, para todos os atores da universidade, com ênfase no desenvolvimento das competências internacionais e interculturais;

- Criação de programas de Dupla-Diplomação para os cursos de graduação e pós-graduação

- Diagnóstico institucional frente aos principais indicadores utilizados pelos rankings internacionais visando um melhor posicionamento da UNIVALI nos principais rankings internacionais sobre as universidades latino-americanas. América Latina.

- Promoção de Programas de graduação lecionados em idioma estrangeiro, com ênfase inicial nos idiomas Inglês e Espanhol.

Para tratar das ações estratégicas de internacionalização, além de suas práticas regulares, a UNIVALI tem uma estrutura institucional específica atualmente denominada de Diretoria de Internacionalização. A Diretoria de Internacionalização (DI) é chefiada por um Diretor, que conta com seus assessores de internacionalização para planejar e executar as diversas práticas/ações de internacionalização que são de sua responsabilidade, como orientar os gestores sobre as tendências do processo de internacionalização universitário, decidir sobre parcerias projetos internacionais estratégicos, preparar e gerenciar acordos internacionais, promover a orientação e a integração de alunos intercambistas, recepcionar visitantes internacionais, dentre outras.

Dentre as principais linhas de ação encontram-se projetos voltados à Internacionalização do Currículo, Internacionalização em Casa, Mobilidade Virtual e projetos online de colaboração virtual (COIL), além de ações estratégicas pela evolução dos indicadores utilizados para a 
avaliação das universidades latino-americanas pelos rankings. Internacionais como o QS e o THE. A principal linha de ação, nesta gestão, é a intensficação dos acordos de cooperação para a Dupla Diplomação com universidades parceiras na Europa e Américas.

A mobilidade internacional discente é um dos componentes do processo de internacionalização. Na UNIVALI, esse processo ocorre também através das ações e estratégias de internacionalização do currículo (IoC) e Internacionalização em Casa (IaH). A intensificação dos programas de intercâmbio na área de ensino ocorre quando a experiência de intercâmbio no exterior, acadêmicos e vivenciais, são usados pelos professores como recursos pedagógicos a evidenciar outras e diversas perspectivas acadêmicas e visões de mundo a enriquecer o currículo e a qualidade da educação.

Os principais resultados alcançados nos programas de intercâmbio, são o desenvolvimento, pelos alunos, de uma maior autonomia, maior consciência sobre identidade cultural e, sobretudo, uma maior percepção sobre as diferentes perspectivas acadêmicas e profissionais. Afirma-se que as parcerias com universidades europeias provaram ser de longo termo e, que em sua maioria, a abrangência da cooperação se ampliou em algumas áreas específicas, como a de Ciências Jurídicas. Com as universidades de Alicante e Perúgia, por exemplo, a UNVALI mantém hoje acordos de Duplo Diploma nos cursos de graduação e Programas de pós-graduação stricto sensu, além de um Programa de Professores Visitantes que regularmente ministram aulas e palestras nas três universidades.

Em 2021, um acordo de cooperação internacional denominado Programa Interuniversidades foi assinado entre a UNVALI e as Universidad de Alicante e L’Università Degli Studi di Perugia. O acordo, na prática, estabelece que as universidades de Alicante e Perúgia passam a contar com um campus universitário dentro da UNIVALI, assim como esta passa a ter um campus nas universidades conveniadas. Ele é resultado da consolidação do trabalho realizado nas últimas décadas pelas universidades conveniadas por meio do ensino e da pesquisa e estimula a formação de equipes de trabalho multiprofissionais entre as instituições, programas de duplo diploma para graduação, mestrado e doutorado, e projetos conjuntos de pesquisa e mobilidade para professores, alunos e funcionários técnicoadministrativos.

Na UNIVALI, existe um fluxo para a assinatura de convênios de cooperação acadêmica e técnico-científica. Estes deverão receber um parecer técnico da Diretoria de Internacionalização, que os direcionará à Vice-Reitoria de Pesquisa e/ou de Graduação, para parecer final. Todos os acordos de cooperação deverão assinados pelo reitor, depois de revisada as questões legais pela Procuradoria da UNIVALI. Quando o acordo envolve recursos 
financeiros, o parecer da Secretaria Executiva também é requerido. É importante mencionar que, muitas vezes, pesquisas são realizadas pelos professores/ pesquisadores, em colaboração ou cooperação com outros colegas de instituições internacionais, sem que um vínculo formal seja firmado inicialmente.

Os principais resultados alcançados, além do objeto da própria pesquisa, são as diversas perspectivas internacionais e interculturais introduzidas pela cooperação ao processo de pesquisa. Surge a necessidade do desenvolvimento, pelos parceiros e pesquisadores, do respeito mútuo e da capacidade de se adaptar aos novos modelos de trabalhar, interagir e resolver problemas. Em termos mensuráveis e concretos, os principais resultados desses programas de colaboração internacional de pesquisas são a oportunidade de mobilidade de alunos e professores, publicação de artigos/ livros em coautoria e a participação dos professores/pesquisadores nas aulas/ programas da graduação e pós-graduação como professores visitantes em ambas as universidades.

No tocante a extensão, diferentemente do que ocorre no ensino e pesquisa, poucos são ainda os projetos e resultados extensionistas que visam a internacionalização da universidade. Uma das principais práticas decorre de um projeto articulado entre o curso de Relações Internacionais (através do extinto Escritório de Relações Internacionais-ERI) e o Mestrado Internacional em Direito das Migrações Transnacionais.

Através de um convênio da UNIVALI com a Polícia Federal, mais de 50 migrantes, de várias nacionalidades, são atendidos, semanalmente, via agendamento para receber auxílio relativos à pedidos de residência, regularização de documentos, refúgio, renovação da carteira de estrangeiro etc. O projeto de extensão faz parte da Cátedra Sérgio Vieira de Melo, uma Cátedra da ACNUR, agência da ONU para Refugiados, coordenada na UNIVALI pelo Prof. Rafael Padilha, coordenador do acima citado Mestrado. O projeto conta ainda com o apoio da OIM, Organização Internacional para Migrações.

A instituição faz, de forma regular e articulada, entre as DI e Vice-Reitoria de Pesquisa, Pós-graduação e Inovação, a divulgação das oportunidades para estudantes e professores sobre oportunidades de estudarem completarem a formação no exterior. A universidade estimula a criação de vínculos com centros universitários e institutos de pesquisa, provendo, sempre que necessário, o apoio institucional aos professores e pesquisadores. A difusão de informações sobre oportunidades ocorre de vários modos: 1- atualização no website da Diretoria de Internacionalização sobre aberturas de editais e oportunidades oferecidas pela UNIVALI e/ou outras instituições/organizações internacionais. 2- Envio de e-mails direcionados à professores, coordenadores e diretores; 3- divulgação nas redes sociais da UNIVALI (Instagram e 
Facebook); 4- Rádio e Tv UNIVALI também são utilizados, sempre que possível, como difusores de informações sobre oportunidades internacionais.

\subsection{UNIVILLE}

A UNIVILLE tem como missão promover formação humanística, científica e profissional para a sociedade por meio do ensino, da pesquisa e da extensão, comprometida com a sustentabilidade socioambiental. E tem como visão ser reconhecida nacionalmente como uma universidade comunitária, sustentável, inovadora, internacionalizada e de referência em ensino, pesquisa e extensão. (PDI, 2021). Nesse sentido, a internacionalização está no âmbito da gestão e orienta o seu planejamento estratégico, por meio da Assessoria Internacional - AI. A AI está ligada à Reitoria e composta por um Assessor com conhecimentos e vivência nas áreas da internacionalização e mobilidade e por um Assistente, responsável pela operacionalização das ações de mobilidade acadêmica. (PDI, 2021).

A AI, por sua vez, como se apresenta no PDI (2021), tem como missão promover a internacionalização curricular da comunidade acadêmica, por meio de projetos e programas, desenvolvidos com base nos Macroprocessos da Política de Internacionalização da instituição. São eles: Modalidade Outgoing e Incoming, Estágio e Pesquisa Internacional, Short Term Programs e Internationalizations at Home (IaH). A Univille oferece, desde 2007, por meio de editais internos, ajuda de custo para pós-doutorado no exterior, acrescidas da manutenção do salário referente às horas de dedicação ao programa. Assim, a Universidade incentiva a internacionalização de seus docentes com redes de cooperação e produção científicas internacionais.

É por meio de uma Política de Internacionalização e Resolução de Mobilidade Acadêmica Internacional, que a UNIVILLE busca fomentar o processo de internacionalização, oportunizando à comunidade acadêmica, a realização de intercâmbios, estágios, pesquisas e programas de curta duração em outros países.

Na competência da AI, tem-se como objetivos (PDI 2021):

- articular a troca de experiências entre estudantes, professores, pesquisadores, pessoal administrativo com seus pares de instituições estrangeiras parceiras;

- $\quad$ promover intercâmbios, cursos, eventos e estágios, no âmbito internacional;

- intensificar a interação da Universidade com as diversas áreas de governo, com instituições de ensino superior, instituiçõos de pesquisa, desenvolvimento e/ou in ovação e com a iniciativa privada, com o propósito de fomentar iniciativas de interna cionalização;

- buscar a interlocução e articulação com as agências nacionais e internacionais financiamento ao desenvolvimento da cooperação e do intercâmbio acadêmico- científico internacional; 
- viabilizar ações de internacionalização de currículo "em casa";

- incentivar a participação da comunidade acadêmica em diferentes tipos de atividades acadêmico-científicas e culturais internacionais; promover e divulgar as atividades da Univille no exterior; fortalecer a posição da Univille como universidade de referência regional nas aarticula ções internacionais.

O ano de 2020, conforme apresenta o Relatório de Atividades da UNIVILLE 2020 (UNIVILLE, 2021), configurou-se globalmente como o ano mais desafiador dos últimos tempos em diversos âmbitos, inclusive para a educação. Assim também foi, em grande proporção, para a área de internacionalização do ensino superior, que buscou e vem buscando novas formas de cumprir com seu papel diante do novo cenário. A mobilidade, as viagens, os intercâmbios e outras experiências presenciais similares deram lugar à virtualização entres as IES e os países do globo.

No início de 2020 as ações de internacionalização da UNIVILLE continuaram sendo trabalhadas acerca dos macroprocessos presentes na Política de Internacionalização, que são: Mobilidade Acadêmica Internacional Outgoing e Incoming; Estágio Internacional; Pesquisa Internacional e Programas de Curta Duração. Após o anúncio da pandemia do novo Corona vírus (Covid 19) no cenário mundial e brasileiro, a maior parte das atividades foi interrompida ou suspensa. Posta essa nova circunstância, o foco foi alterado para atividades on-line de Internationalization at Home ( $\mathrm{IaH})$, ou "Internacionalização em Casa", com as Disciplinas Curriculares e Módulos Interdisciplinares, ambos em inglês, participação e promoção de webinários internacionais, lives e aulas ministradas por professores da UNIVILLE e de universidades estrangeiras, além da continuidade de parcerias para o desenvolvimento de projetos de pesquisa com parceiros internacionais.

A seguir estão os resultados das ações de 2020, por macroprocesso:

1. Programa de Mobilidade Acadêmica Internacional (PMAI) - Outgoing - Este programa visa enviar estudantes da UNIVILLE para frequentar disciplinas do seu curso de graduação no exterior por um período de 6 ou 11 meses, dependendo da matriz curricular (semestral ou anual). O PMAI Outgoing em 2020 teve sua campanha de comunicação realizada no mês de fevereiro e o edital publicado na sequência. Dezessete estudantes se inscreveram, contudo, por conta da instabilidade e do começo da crise pandêmica, todos os inscritos optaram por não realizar a atividade, do mesmo modo que os participantes do PMAI Outgoing 2019/2020 retornaram nos meses seguintes.

2. Programa de Mobilidade Acadêmica Internacional (PMAI) - Incoming - Este programa visa receber na Universidade estudantes e professores de universidades estrangeiras 
parceiras, para cursar disciplinas do seu respectivo curso de graduação, sejam elas teóricas ou práticas. Em 27 de fevereiro de 2020 recebemos o médico recém-formado Doutor Immanuel Adam, da Alemanha, estudante de Mestrado em Bioética da Universidade de Jena. Seu propósito de visita foi para compreender o funcionamento do SUS e da saúde pública brasileira. A UNIVILLE organizou uma agenda que contemplou sua participação em atendimentos clínicos no Ambulatório da Universidade, assim como em cirurgias e consultas em hospitais conveniados a universidades. No entanto, em razão da instabilidade referente à pandemia, acabou retornando a seu país no início de abril.

3. Estágio Internacional - Os estágios internacionais são períodos de atividades práticas realizadas em instituições ou empresas no exterior. Os estágios podem ser extracurriculares ou curriculares. Os extracurriculares são os não obrigatórios para o currículo acadêmico e podem durar até 3 meses. Já os curriculares são os previstos em matriz curricular do curso e podem durar de 6 meses a 1 ano. Em janeiro de 2020 a UNIVILLE filiou-se à Associação Americana de Faculdades de Medicina (AAMC), para ter acesso ao Programa VSLO, uma plataforma global de estágios internacionais da sa.de que auxilia estudantes a se conectarem com instituições que oferecem oportunidades eletivas de curto prazo e assim se aprimorarem em sua educação médica. Essas oportunidades incluem estágios de observação, programas de pesquisa, oportunidades clínicas e de visitas. Os estágios poderão ser realizados assim que a situação de pandemia terminar.

4. Pesquisa Internacional - A Pesquisa Internacional compartilha e frutifica o conhecimento conjunto com instituições acadêmico-cientificas estrangeiras, fortalecendo as redes de cooperação internacional da Universidade. Em 2020 a UNIVILLE estreitou os laços com a Concordia University of Edmonton (CUE), Canadá, para a realização de um projeto de pesquisa conjunta na área de Engenharia de Software e Inteligência Artificial. O projeto "Flood Prediction”, do Prof. Dr. Paulo Marcondes Bousfield, prevê a possibilidade de enchentes e permite determinado controle por meio de um software. $\mathrm{O}$ objetivo da pesquisa é aprimorar o projeto com mais estudos por parte do Concordia Centre for Applied Artificial Intelligence CCA2I.

5. Seminário Internacional On-line - Em maio de 2020, ocorreu a primeira Human Service Week, em forma de evento on-line promovido pela Evangelische Hochschule Nürnberg (EVHN), uma universidade alemã conveniada à UNIVILLE. O tema do evento foi a importância da assistência social durante a crise/pandemia, e contou com a participação de diversos professores parceiros do mundo todo, entre eles a professora da UNIVILLE, Profa. Dra. Jurema Tomelin. O estudante de Comércio Exterior e participante do seminário, Bruno 
Rezende, concedeu entrevista ao jornal alemão da cidade de Nuremberg, relatando sua experiência em um evento com esse tema e formato.

6. Internationalization at Home (IaH) - Internacionalização em Casa - O Internationalization at Home - macroprocesso que se tornou o carro-chefe das ações de internacionalização da UNIVILLE em 2020 - é o termo usado para o desenvolvimento de estratégias e ferramentas de internacionalização do currículo on campus, isto é, sem viajar, de maneira economicamente mais viável. Em seguida, todas as nossas atividades relacionadas ao IAH:

6.1 Disciplinas curriculares em inglês (DCIs) - Disciplinas contempladas nas matrizes curriculares de cursos de graduação da UNIVILLE, ministradas em inglês. Para 2020 foram ofertadas quatro DCIs e uma DCI optativa (Resolução de Conflitos). Das cinco DCIs oferecidas, três tiveram abertura de turmas.

6.2 Módulos Interdisciplinares em inglês - Cursos de extensão de 36 h/a ministrados em inglês gratuitamente aos estudantes da UNIVILLE. O objetivo é viabilizar a prática do idioma por meio de conteúdos da área de interesse do estudante. Em 2020 as aulas dos módulos passaram a ser on-line, com os seguintes temas: Sustainable Development Goals e Quality Tools.

6.3 Professor Visitante Estrangeiro - No final do mês de fevereiro, a convite de nosso Professor Doutor Pedro Jorge Cortes Morales, recebemos o também Professor Doutor Pedro Valdívia Moral, da Universidade de Granada (Espanha), para a divulgação de sua palestra “Atividade física na perspectiva da igualdade de gênero", voltada para o público de Educação Física. O evento também fez parte da celebração dos 50 anos do curso.

6.4 Webinários de Internacionalização Acafe - O primeiro webinário, realizado no dia 10 de junho, teve como tema "O futuro da internacionalização no ensino superior", com a participação dos professores palestrantes Marília Morosini (PUC/RS), Luciana Stallivieri (UFSC) e Nicolas Mailard (UFRGS), e contou com mais de 120 participantes simultâneos.

6.5 Aula internacional no curso de Design - Em outubro foi realizada uma aula internacional on-line, entre uma turma do segundo ano de Design da UNIVILLE, coordenada pelo professor Roy Schulenburg e o professor Leonardo Colin, e uma turma também de Design da universidade canadense Mohawk University. O objetivo do encontro foi mesclar as informações de principais eventos que ocorrem em Joinville e na cidade de Hamilton (cidade da instituição canadense). Foi escolhido o Festival de Dança de Joinville como tema para os canadenses trabalharem e um evento popular de Ontário, “Around the Bay Road Race”, para os alunos de Design.

Finalizamos, em relação às ações da AI no ano de 2020, reforçando que a internacionalização é tema presente na visão e no Planejamento Estratégico Institucional da UNIVILLE, que, como 
instituição, tem o objetivo de inserir cada vez mais professores, pesquisadores e estudantes no contexto internacional, por meio de projetos e programas de internacionalização curricular.

\subsection{UNOCHAPECÓ}

A internacionalização na UNOCHAPECÓ só ascendeu ao nível das prioridades no ano de 2008. Até então, as ações de internacionalização ocorriam de modo esparso e fragmentado. Naquele momento, outras instituições do país e do próprio sistema ACAFE já possuíam experiências consolidadas nesse campo, sinalizando a urgência da Universidade superar essa lacuna e inserir-se no cenário internacional.

A partir da decisão de implementar atividades de internacionalização de modo permanente, inseridas regularmente, no contexto das atividades acadêmicas, o primeiro passo dado foi a criação da Assessoria de Relações Nacionais e Internacionais da UNOCHAPECÓ (ARNI), por meio da reforma político-administrativa e incluída no Regimento Geral da Universidade. Criada a Assessoria, o primeiro desafio lançado foi a institucionalização das atividades mais elementares ligadas ao tema, como a definição dos procedimentos acadêmicos e administrativos necessários à prática da mobilidade acadêmica.

Essa atividade se estendeu ao longo dos anos de 2008 a 2010 e logrou êxito em criar o Regulamento de Cooperação e Mobilidade Acadêmica, o qual institui procedimentos básicos necessários à vinda e envio de estudantes em mobilidade acadêmica. Com o passar dos anos a internacionalização a ser instituída nos documentos institucionais oficiais como Plano de Desenvolvimento Institucional e a Política de Internacionalização que tem como objetivos contribuir para o desenvolvimento acadêmico, científico e tecnológico da região; promover a mobilidade discente, docente e de técnicos-administrativos da Universidade; constituir-se num diferencial competitivo da Universidade, fortalecendo a marca UNICHAPECÓ; implementar a cooperação internacional em pesquisa e inovação em todos os níveis de ensino; consolidar a

oferta de ensino virtual conectada com as demandas mundiais; contribuir para o desenvolvimento acadêmico por meio de experiências de aprendizagem inovadoras.

Paralelamente, a ARNI passa a difundir a ideia da internacionalização junto à comunidade acadêmica, por meio de diversas iniciativas como mobilidade acadêmica para discentes e docentes, curso de língua estrangeira, estágios internacionais, visitas técnicas, participação em eventos internacionais e projetos com intercambistas. Outra oportunidade importante foi a celebração de convênios com instituições estrangeiras com o objetivo de possibilitar o intercâmbio discente e docente, o desenvolvimento de projetos e pesquisas 
conjuntos, promoção de eventos científicos, oferta de cursos conjuntos, bem como o aprimoramento de línguas estrangeiras. Com isso, a comunidade acadêmica tem tido a oportunidade de desenvolver intercâmbios acadêmicos e científicos, que proporcionam o desenvolvimento de parte do curso de graduação, pós-graduação ou de atividades de pesquisa em outra instituição de ensino no exterior.

A partir de então os estudantes da UNICHAPECÓ passaram a compreender a mobilidade acadêmica como uma possibilidade de ampliar suas experiências educativas, e o número de intercambistas passou a crescer, tendo-se percebido um aumento significativo de estudantes, principalmente de graduação, em mobilidade acadêmica, estágio ou cursos de idiomas no exterior. Com os programas institucionalizados iniciou-se também a vinda de estudantes e docentes estrangeiros na UNOCHAPECÓ para participar de diferentes atividades acadêmicas. As vivências internacionais entre os estudantes possibilitam trocas acadêmicas, pessoais e profissionais que contribuem para sua formação e também enquanto cidadão global. Apesar de uma oportunidade muito enriquecedora para o estudante, uma minoria tem condições de participar desse tipo de intercâmbio acadêmico, pois envolvem recursos, tempo, idiomas dentre outros, que podem ser dificultadores para alguns estudantes.

Por isso, ações para a internacionalização em casa são desenvolvidas com o intuito de possibilitar experiências internacionais e interculturais para um número maior de estudantes e docentes. Destacamos a mobilidade virtual, que permite o estudante cursar componentes curriculares virtualmente em uma universidade estrangeira parceira e os estudantes internacionais podem cursar de forma síncrona componentes curriculares nos diferentes cursos de graduação e pós-graduação que são ofertados na Universidade. Alguns desses componentes são ofertados em língua estrangeira, possibilitando a participação de um número maior de estudantes estrangeiros.

Outra ação que já ocorria, mas que vem ganhando força é o intercâmbio virtual, também conhecido como COIL (Collaborative online international learning), ou seja, refere-se a atividades, aulas, projetos conjuntos entre professores e estudantes, com interesses semelhantes que queiram compartilhar conhecimento e buscar soluções para problemas locais e ainda proporcionar aos estudantes desenvolvimento de competências interculturais, as quais destacamos: gerenciamento de situações de liderança e motivação, melhorar habilidades de comunicação, interculturalidade, interagir, participar e colaborar com pessoas de diferentes culturas. Além dessas ações, muitas lives, palestras, workshops, conferências foram realizadas virtualmente com a presença de estudantes e professores estrangeiros nos diferentes cursos de graduação e pós-graduação. Todas essas ações foram facilitadas pelo acesso e uso de 
tecnologias digitais, possibilitando assim, o fortalecimento dessas ações e de maneira significativa, ampliando a cooperação e a internacionalização em casa e no currículo.

Os Programas de Pós-Graduação Stricto Sensu também apresentam avanços expressivos e inovadores no cenário internacional, com diferentes ações e projetos que contribuem de forma positiva para a internacionalização do ensino superior. Existe uma forte relação entre professores e pesquisadores internacionais para o desenvolvimento de pesquisas, projetos e publicações conjuntas internacionais, participação em redes internacionais, co-orientação de dissertações/teses e bancas avaliadoras em IES estrangeiras, realização de eventos internacionais, incentivo a participação dos docentes em atividade pós-doutoral no exterior, atividades de difusão e de transferência de conhecimento e tecnologia em nível internacional; incentivo à mobilidade acadêmica e oferta de componentes curriculares em língua estrangeira, presença de professores estrangeiros para ministrar aulas, palestras, pesquisas, participação em editais internacionais para fomento da pesquisa.

Essas ações fortalecem as pesquisas, aumentam a visibilidade e credibilidade do estudo, além de promover o intercâmbio dos pesquisadores e também dos discentes, gerando novas ações entre si. O intercâmbio de discentes têm aumentado e a presença de professores internacionais na instituição também.

A Extensão Universitária na UNOCHAPECÓ objetiva transformar o saber acadêmico em bem público, ampliando a formação do ser humano para a prática do exercício profissional. Dentre os objetivos e diretrizes da extensão universitária destaca-se a busca pela ampliação e fortalecimento das ações de extensão interinstitucionais e as atividades voltadas para o intercâmbio e a internacionalização por meio de redes ou parcerias, as quais podem ser desenvolvidas tanto pela promoção de eventos e cursos ou mesmo pela promoção de ações de projetos e programas de extensão em parceria com instituições estrangeiras.

Destacamos o curso “Objetivos de Desenvolvimento Sustentável e boas práticas”, foi desenvolvido com a Universidade de Guadalajara no México com o objetivo de contribuir para a formação e capacitação de diferentes atores do setor da educação para que sejam defensores e promotores da implementação dos Objetivos de Desenvolvimento Sustentável nas suas comunidades e organizações. O curso é bilíngue e está na Plataforma virtual Unoplus da UNOCHAPECÓ.

Outro curso que está disponível na plataforma Unoplus é o curso de Português para estrangeiros e tem como objetivo apresentar estruturas gramaticais, vocabulário e usos mais recorrentes da língua portuguesa para falantes de outras línguas. A promoção de um curso de português como língua estrangeira é de suma importância em uma universidade em processo 
de internacionalização, uma vez que deve ter preocupação com a integração dos novos estudantes. Este curso apresenta-se como um diferencial da UNOCHAPECÓ para atrair novos intercambistas, pois há uma escassez de cursos de português voltado para falantes de outras línguas. Além disso, o curso poderá também ser adquirido por intercambistas optantes por outros destinos.

Para promover o ensino de línguas da comunidade acadêmica, a universidade criou em desde 2005, o Laboratório de Línguas da UNOCHAPECÓ (LABLIN), o qual está vinculado ao curso de graduação em Letras Português/ Inglês, e por meio dele são ofertados cursos de línguas estrangeiras presenciais e ampliou suas propostas com cursos virtuais para os estudantes locais e estrangeiros. A instituição também passou a oferecer aprendizagem de línguas por meio de uma plataforma virtual, com a oferta de mais de 20 diferentes idiomas, de forma gratuita, dando assim, mais possibilidade de acesso para toda a comunidade acadêmica, que podem realizar os cursos de forma assíncrona.

\section{Considerações finais}

A UFSC iniciou o processo de internacionalização no início da década de setenta do século passado, com o Programa de Convênio Estudante de Graduação, criado em 1972. Na sua gênese, o Escritório de Assuntos Internacionais era responsável pelas ações internacionalizantes, sendo no curso do desenvolvimento substituído pela, hoje, Secretaria de Relações Internacionais, órgão vinculado a Reitoria. Com tantos anos já envolvida nesse projeto, e com cursos de graduação e pós-graduação de excelência, cresceram os acordos de cooperação internacionais. Registros apontam que nos últimos anos esses chegam próximo de 400. Programas a movimentação de estudantes como incoming e outcoming, dão apoio a recebimento de estudantes do exterior, bem como de estímulo a estudantes brasileiros frequentarem universidades no exterior., constituem uma das referências. Nessa linha, a universidade envia anualmente cerca de 170 alunos para o exterior. Programas internacionais com países latino-americanos - Uruguai, Colômbia, Argentia e México - existem para recebimento de alunos estrangeiros.

Outros programas ativos estão presentes, na UFSC como o Idiomas sem Fronteiras destinado a internacionalização do ensino e os associados a University Studies Abroad Consortion, Universiteit Leiden e University of Hradec Králove que concedem bolsas de estudo para alunos de graduação e de pós-graduação para frequentarem diferentes áreas de ensino no exterior. Também, há o programa Jovenes Lideres Iberoamericanos destinado para egressos de 
cursos de graduação para realização de intercâmbio em Madrid, Espanha. No âmbito da pesquisa, são vários projetos envolvendo professores e alunos, destacando os vinculados aos cursos de Engenharia, com universidades estrangeiras. Assim como, existem convênios de pesquisa em que colaboradores estrangeiros encontram-se presentes. E, no campo da extensão, conta com núcleo institucional de ensino que oferece diversos cursos em inúmeros idiomas à comunidade, bem como realiza anualmente eventos com parceiros internacionais aberto à sociedade.

A UDESC estabeleceu no início dos anos 2000 compromisso com a cooperação acadêmica internacional com elaboração de plano estratégico para o período de 2005-2025, cujas ações são reforçadas nos planejamentos estratégicos quadrienais, como o de 2020-2024. Desenvolve projetos em que mobiliza os cursos de graduação e os programas de pós-graduação a se internacionalizarem. Da mesma forma, possui projetos que estimulam tais instâncias a fazerem parcerias internacionais. Para tanto, conta com Secretaria de Cooperação Interinstitucional e Internacional, órgão que cria acordos de cooperação no contexto internacional. Nessa linha, a UDESC possui convênios com 22 universidades de vários países, destaque para a Alemanha, Austrália, Canadá, Chile, Itália, Coreia do Sul, Estados Unidos e Argentina. O Programa de Mobilidade Estudantil permite a realização de disciplinas e outras atividades acadêmicas em universidades estrangeiras, sendo programa bem ativo, cada semana 12 alunos recebem auxílio para estudar um semestre no exterior.

Desenvolve a UDESC outros programas como Intercâmbio e Mobilidade Acadêmica com recebimento de estudantes estrangeiro de universidade conveniada. A Universidade oferece disciplinas em inglês em várias áreas do conhecimento. Mantem também, o Programa Apadrinhamento/Buddy com vistas a orientar o estudante estrangeiro em seus primeiros passos no país. Tem em sua estrutura recente o escritório Education USA voltado a dar informação a estudantes que desejam estudar no exterior. Conta com o Programa de Auxílio a Participação em Eventos, que estimula a participação em congressos internacionais, bem como o Programa de Auxílio a Internacionalização da Pós-Graduação voltado em apoiar professores a participarem de atividades de pesquisa ou pós-graduação no exterior. E, no tocante a ações de extensão, destaque para o vínculo com o programa de cooperação humanitária internacional das Nações Unidas em projeto de gestão de riscos e desastres, firmado através de convênio com organismo internacional USAID/OFDA.

A FURB desenvolve programa de internacionalização de suas atividades por 23 anos. Nesse curso, os resultados alcançados são frutos de política de internacionalização institucionalizada, que desenha ações sustentadas por planos estratégicos elaborado ao longo 
dos anos. Há uma Coordenadoria de Relações Internacionais que promove a internacionalização da instituição. Dentro do quadro de resultados, tem-se parcerias firmadas com cerca de 70 universidades em mais de 20 países, sendo que, atualmente, está em vigor convênios com 10 países da América do Sul, 9 da Europa, 3 da África e 2 da Ásia. As parcerias com universidades de países como a Alemanha, China, Argentina e Canada, alcançaram o número de 72. No âmbito da mobilidade acadêmica, em 2017, foram enviados ao exterior 71 estudantes e 5 professores e acolhidos 27 alunos e 3 professores para desenvolvimento de atividades de ensino, pesquisa e extensão.

Ressalta-se, também, na FURB o fomento a internacionalização relacionado ao estudante cursar disciplinas lecionadas em inglês, espanhol e alemão em universidades conveniadas, como ocorre no curso de Tecnologia em Marketing com a Universidade de Halmsyad, em que o aluno pode obter dupla diplomação. Cita-se também, o programa de extensão universitária internacionalizante, denominado Amigos do Mundo, em que incentiva a comunidade receber estudantes estrangeiros de universidades conveniadas em residências na cidade de Blumenau.

Na UNESC, há uma política de internacionalização aprovada institucionalmente com orientações voltada a ampliação da estrutura de internacionalização, qualificação do corpo docente e discente em língua estrangeira, potencialização de parcerias e acordos de cooperação com instituições estrangeiras e fortalecimento dos programas de pós-graduação stricto sensu. Conta com o escritório de Relações Internacionais que mantem várias ações dentre as quais recepção de visitantes, negociação e condução de acordos de cooperação, apoio em solução de processos administrativos de estrangeiros, entre outras ações. Atualmente, a universidade mantém 47 acordos e convênios internacionais com diferentes universidades no exterior, com destaque para os países: Alemanha, Canadá, EUA, França, Inglaterra, Espanha, Chile, Angola e Argentina.

A UNESC desenvolve vários programas dentre esses o de Mobilidade Acadêmica, que registrou o envio de 109 estudantes de graduação e 2 pós-graduação ao exterior, bem como recebeu de 29 alunos estrangeiros 1 de pós-graduação e 12 para o programa Residência Multiprofissional. Destaque, também, para o número significativo de cursos, 202 minicursos e complementações cursadas por alunos e professores em diferentes convênios realizados, até o momento. Além, da universidade oferecer apoio a internacionalização de estudantes não só aos da própria instituição como aberto a comunidade, via Instituto de Idiomas, em cursos de idiomas como alemão, inglês, espanhol, italiano, francês e português. 
Na UNIVALI, a prática de internacionalização de atividades iniciou no começo dos anos 1990 com a criação da Assessoria de Assuntos Internacionais. A internacionalização das atividades insere-se essa no planejamento estratégico da universidade, que norteia a Política de Internacionalização. O último plano de 2016 a 2021 conta objetivos de firmamento de acordos de cooperação internacional. As ações internacionalizantes têm-se voltado para o desenvolvimento de vários programas como a internacionalização do currículo, internacionalização em casa, mobilidade virtual, projetos on line de colaboração virtual, além de outras ações como as voltadas em alcançar indicadores utilizados para universidades latinoamericana melhor se posicionarem nos rankings internacionais.

Dentre as parcerias realizadas citam-se as com universidades europeias: Universidad di Alicante e Universidad Degli Studi di Perúgia. Nessas parcerias firmadas permite-se o duplo diploma nos cursos de graduação e em programas de pós-graduação strictu-sensu, tanto para os estudantes brasileiros como para os estrangeiros. No âmbito da extensão, a UNIVALI tem convênio com a Polícia Federal, através para atendimento de migrantes de várias nacionalidades em ações voltadas no auxílio a regularização de documentos, pedidos de residência, apoio a refugiados, etc. Até o momento, os programas de colaboração internacional, no geral, têm possibilitado a mobilidade de alunos e professores para realização de cursos e pesquisa com pares no exterior, publicação de artigos e livros em co-autoria e participação de professores estrangeiros visitantes em projetos internos, bem como de professores da Univali em programas de pós-graduação em universidades conveniadas no exterior.

A UNIVILLE possui a Assessoria Internacional, ligada a Reitoria, que tem como propósito auxiliar a gestão do processo de internacionalização da universidade. Essa instância orienta projetos e programas voltados à internacionalização do ensino, pesquisa e extensão universitária. O planejamento estratégico dá destaque a essas atividades. Dentre das práticas existentes, realçam-se os programas de mobilidade acadêmica internacional, na linha outgoin, com informação que 17 estudantes se inscreveram para desenvolverem atividades de ensino no exterior. E, na linha incoming, possui estrutura para receber estudantes de outros países, sendo referência a vinda de estudante de mestrado da Universidade de Jena, da Alemanha. Possui o programa de estágio internacional em atividades curriculares e extracurriculares, sendo que na última o estudante pode ficar até 3 meses no exterior; enquanto, na primeira o estudante pode ficar de 6 meses a 12 meses. Conta como referência, a aquisição da plataforma VSLO de estágios internacionais que oferece oportunidades para a comunidade acadêmica;

No âmbito da pesquisa, a UNIVILLE possui cooperação com a Concordia Univerity of Edmonton do Canadá para realização de pesquisa na área de Engenharia de Software e Inteligência Artificial. Além disso, destacam-se a realização de seminários internacionais, sendo citado o realizado 
com a Evangelische Hochschule Nurnberg da Alemanha com participação de professores e alunos, e o programa em Internationalization at Home com oferta de disciplina em inglês. Conta, também, com cursos de extensão ministrados em inglês e webinário internacionalizado para a realização de palestras e aulas internacionais abertas, em que participam alunos e professores da instituição e de universidades estrangeiras. Cita-se, nesse último, a aula internacional ministrada no curso de Design, em participação conjunta com a universidade canadense Mohawk University.

Na UNOCHAPECÓ são destacadas várias práticas internacionalizantes levadas a cabo pela instituição. Destaca-se a mobilidade virtual que possibilita o estudante cursar de forma síncrona disciplinas de cursos de graduação e pós-graduação em universidades estrangeiras. Segue-se, também, o programa de intercâmbio virtual, Collaborative Online Intenational Learningem, aberto para professores e alunos com interesses semelhantes na busca de soluções interculturais junto com pares de universidades estrangeiras, via live, palestras workshops e conferências. Ressalta-se, também, o desenvolvimento de projetos de pesquisas conjuntos com professores e pesquisadores estrangeiros, somada a participação em redes internacionais via co-orientação de dissertações e teses e participação de professores em atividades de pós-doutorado no exterior.

No campo da extensão universitária, agregam-se às atividades de extensão interinstitucionais internacionais, as práticas de desenvolvimento sustentável. Em andamento, o convênio firmado com a Universidade de Guadalajara do México para desenvolvimento de ações dos objetivos do milênio da ONU nas comunidades e organizações. Cita-se, ainda outra prática voltada ao ensino de português para estrangeiros com objetivo de integração maior desses estudantes por meio da plataforma Unoplus, somada, também ao ensino de idiomas à comunidade acadêmica e à sociedade em geral, em atividades do Laboratório de Línguas com oferta de 20 diferentes idiomas.

\section{Referências}

BRASIL. Lei Federal no 12.881, de 12 de novembro 2013. Dispõe sobre a definição, qualificação, prerrogativas e finalidades das Instituições Comunitárias de Educação Superior ICES, disciplina o Termo de Parceria e dá outras providências. Disponível em: https://www.planalto.gov.br/ccivil_03/_ato2011-2014/2013/lei/112881.htm. Acesso em 15 de ago. de 2021.

CARVALHO, S. ARAÚJO, G. Gestão da internacionalização das instituições de ensino superior. Avaliação: Revista da Avaliação da Educação Superior (Campinas), p. 113-131, 2020. Disponível em: https://doi.org/10.1590/S1414-40772020000100007. Acesso em 2 maio. 2021.

FURB. Plano de Desenvolvimento Institucional - PDI - 2014: disponível em https://www.furb.br/_upl/files/avaliacao_institucional/PDI\%202010_2015.pdf?202108292043 11. Acesso em 15 de ago. de 2021. 
FURB. Plano de Desenvolvimento Institucional - PDI - 2017: disponível em https://www.furb.br/_upl/files/avaliacao_institucional/PDI\%202016_2020.pdf?202108292043 11. Acesso em 15 de ago. de 2021.

FURB. Plano de Desenvolvimento Institucional - PDI - 2018: disponível em https://www.furb.br/_upl/files/avaliacao_institucional/PDI\%202016_2020\%20REVISAO\%20 2018\%20CONSUNI.pdf?20210829204311. Acesso em 15 de ago. de 2021.

FURB. Relatório Institucional de Atividades 1998. Blumenau, 2021. Disponível em https://bu.furb.br/CMU/relatoriosFURB/1998\%20Relatorio.pdf Acesso em 25 de ago. de 2021.

FURB. Relatório Institucional de Atividades 2012. Blumenau, 2021. Disponível em https://bu.furb.br/CMU/relatoriosFURB/RELATORIOINSTITUCIONAL-2012pdfa.pdf Acesso em 25 de ago. de 2021.

FURB. Relatório Institucional de Atividades 2015. Blumenau, 2021. Disponível em https://bu.furb.br/CMU/relatoriosFURB/RELATORIOINSTITUCIONAL-2015pdfa.pdf Acesso em 25 de ago. de 2021.

SILVA, W. C. A internacionalização em casa como ferramenta para promoção de uma internacionalização inclusiva: o caso da Universidade Federal de Santa Catarina. Trabalho de Conclusão de Curso. Relações Internacionais. UFSC, 2021. Disponível em: https://repositorio.ufsc.br/bitstream/handle/123456789/222909/Willian\%20-\%20TCC\%20$\% 20$ Versao $\% 20$ Final $\% 20 \% 28$ entrega\%20assinado $\% 29$.pdf? sequence $=1 \&$ isAllowed $=y$.

Acesso em: 10 jul. 2021.

STALLIVIERI, L. O processo de internacionalização nas instituições de ensino superior. Educação Brasileira, Brasília, v. 24, n. 48, p. 35-57, 2002.

SINTER. Sobre a Sinter. Disponível em: https://sinter.ufsc.br/sobreasinter/ Acesso em:2 maio 2021.

SINTER. História da internacionalização da UFSC. Disponível em: https://sinter.ufsc.br/historia-da-internacionalizacao-da-ufsc/. Acesso em: 2 maio 2021.

SINTER. Relatórios de atividade Sinter 2020. Disponível em: https://arquivos.ufsc.br/f/70968154136e46499a34/. Acesso em: 2 maio 2021.

SINTER. Plano Institucional de Internacionalização. Disponível em: https://novaprpg.paginas.ufsc.br/files/2019/02/PROPOSTA-DE-PLANO-INSTITUCIONALDE-INTERNACIONALIZAC\%CC\%A7A\%CC\%83O-Final-Aprovada.pdf. Acesso em maio 2021.

RELAÇÕES INTERNACIONAIS: Disponível em: https://www.furb.br/web/1651/institucional/relacoes-internacionais/apresentacao. Acesso em 15 de ago. de 2021.

RESOLUÇÃO no 03/2018/CONSU. Aprova Política de Internacionalização da UNESC.

UDESC. Plano $20 \quad$ - $\quad$ 2005-2025. 2005. Disponível em: http://www1.udesc.br/arquivos/id_submenu/1005/plano_20_2005_2025.pdf. Acesso em: 23 de jul. de 2021. 
UDESC. Regimento Geral da UDESC. 2007. Disponível em: http://www1.udesc.br/arquivos/id_submenu/782/regimento_geral_da_udesc.pdf . Acesso em: 23 de jul. de 2021.

UDESC. Relatório de Gestão 2004-2008. 2008. Disponível em: http://www1.udesc.br/arquivos/id_submenu/430/relatorio_de_gestao_udesc_2004_2008.pdf. Acesso em: 23 de jul. de 2021.

UDESC. Regimento Geral da Pós-Graduação (Res. 013/2014 - CONSEPE). 2014. Disponível em: http://secon.udesc.br/consepe/resol/2014/013-2014-cpe.pdf. Acesso em: 23 de jul. de 2021.

UDESC. Plano de Desenvolvimento Institucional - PDI -2020 - 2024. 2016. Disponível em: https://www.udesc.br/arquivos/udesc/id_cpmenu/10766/Planejamento_Estrat_gico_20_24_v_ final_16189568652129_10766.pdf. Acesso em: 23 de jul. de 2021.

UDESC. Relatório de Gestão 2017. 2017. Disponível em: https://www.udesc.br/arquivos/udesc/id_cpmenu/2251/Relat_rio_de_Gest_o_2017_FINAL_1 5313328423257_2251.pdf. Acesso em: 23 de jul. de 2021.

UDESC. Revista Retrospectiva UDESC. Edição No 2, 2018. Disponível em: https://www.udesc.br/arquivos/udesc/documentos/revista_retrospectiva_ed2_1523549361864 7_3011.pdf. Acesso em: 23 de jul. de 2021.

UDESC. Revista Retrospectiva UDESC. Edição No 3, 2019. Disponível em: https://www.udesc.br/arquivos/udesc/documentos/revista_retrospectiva_2019_155509590668 57_3011.pdf. Acesso em: 23 de jul. de 2021.

UDESC. Relatório de Gestão 2020. 2020a. Disponível em: https://www.udesc.br/arquivos/udesc/id_cpmenu/10753/Relat_rio_de_Gest_o_Udesc_2020_E nviado_23_02_2020_16189549355332_10753.pdf. Acesso em: 23 de jul. de 2021.

UDESC. Relatório de Gestão da PROPPG. 2020b. Disponível em: https://www.udesc.br/arquivos/udesc/id_cpmenu/3722/RELATORIO_DE_GESTAO_PROPP G_2020_final_1612546501832_3722.pdf. Acesso em: 23 de jul. de 2021.

UDESC. Relatório de Gestão da PROEX. 2020c. Disponível em: https://www.udesc.br/arquivos/udesc/documentos/Realiza_es_da_Proex_Udesc_Gest_o_201 6_20_15862257579984_12035.pdf. Acesso em: 23 de jul. de 2021.

UDESC. Planejamento Estratégico 2020-2024. 2021a. Disponível em: https://www.udesc.br/arquivos/udesc/id_cpmenu/10766/Planejamento_Estrat_gico_20_24_v_ final_16189568652129_10766.pdf. Acesso em: 23 de jul. de 2021.

UDESC. Secretaria de Cooperação Interinstitucional e Internacional. 2021b. Disponível em: https://www.udesc.br/secretaria/scii. Acesso em: 27 de jul. de 2021.

UDESC. Revista Retrospectiva UDESC. Edição No 5, 2021c. Disponível em: 
https://www.udesc.br/arquivos/udesc/id_cpmenu/2029/retro2021_16185148669804_2029.pdf Acesso em: 23 de jul. de 2021.

UFSC. Plano de Desenvolvimento Institucional - PDI - 2020- 2024. Disponível em: https://pdi.ufsc.br/files/2020/06/PDI-2020-2024.pd. Acesso em 2 maio 2021.

UFSC. Plano Anual 2021. Disponível em: https://pdi.paginas.ufsc.br/files/2021/04/PlanoAnual-2021.pdf. Acesso em 2 maio 2021.

UNESC. Plano de Desenvolvimento Institucional - PDI 2018 - 2022. Disponível em: http://www.unesc.net/portal/resources/official_documents/17885.pdf?1575054223. Acesso em 2 maio 2021.

UNESC. Relatório de Autoavaliação Institucional da Universidade do Extremo Sul Catarinense $\quad$ - $2018 . \quad$ Disponível em: http://www.unesc.net/portal/resources/files/263/relatorio_2018.pdf. Acesso em 2 maio 2021.

UNIVILLE. Plano de Desenvolvimento Institucional - PDI - 2017-2021. Universidade da Região de Joinville - Univille. Joinville, SC: Editora Univille, 2021.

UNIVILLE. Relatório de Atividades Univille 2020. Universidade da Região de Joinville. Joinville, SC: Editora Univille, 2021. 